\title{
Storms Producing Large Accumulations of Small Hail $\mathscr{O}$
}

\author{
MATTHEW R. KUMJIAN \\ Department of Meteorology and Atmospheric Science, The Pennsylvania State University, \\ University Park, Pennsylvania \\ ZACHARY J. LEBO \\ Department of Atmospheric Sciences, University of Wyoming, Laramie, Wyoming \\ AARON M. WARD \\ National Weather Service, Amarillo, Texas
}

(Manuscript received 17 March 2018, in final form 12 November 2018)

\begin{abstract}
Hail-bearing storms produce substantial socioeconomic impacts each year, yet challenges remain in forecasting the type of hail threat supported by a given environment and in using radar to estimate hail sizes more accurately. One class of hail threat is storms producing large accumulations of small hail (SPLASH). This paper presents an analysis of the environments and polarimetric radar characteristics of such storms. Thirteen SPLASH events were selected to encompass a broad range of geographic regions and times of year. Rapid Refresh model output was used to characterize the mesoscale environments associated with each case. This analysis reveals that a range of environments can support SPLASH cases; however, some commonalities included large precipitable water (exceeding that day's climatological 90th-percentile values), CAPE $<2500 \mathrm{~J} \mathrm{~kg}^{-1}$, weak storm-relative wind speeds $\left(<10 \mathrm{~m} \mathrm{~s}^{-1}\right)$ in the lowest few kilometers of the troposphere, and a weak component of the storm-relative flow orthogonal to the $0-6-\mathrm{km}$ shear vector. Most of the storms were weak supercells that featured distinctive S-band radar signatures, including compact $\left(<200 \mathrm{~km}^{2}\right)$ regions of reflectivity factor $>60 \mathrm{dBZ}$, significant differential attenuation evident as negative differential reflectivity extending downrange of the hail core, and anomalously large specific differential phase $K_{\mathrm{DP}}$. The $K_{\text {DP }}$ values often approached or exceeded the operational color scale's upper limit $\left(10.7^{\circ} \mathrm{km}^{-1}\right)$; reprocessing the level-II data revealed $K_{\mathrm{DP}}>17^{\circ} \mathrm{km}^{-1}$, the highest documented in precipitation at $\mathrm{S}$ band. Electromagnetic scattering calculations using the T-matrix method confirm that large quantities of small melting hail mixed with heavy rain can plausibly explain the observed radar signatures.
\end{abstract}

\section{Motivation}

Each year, severe convective storms in the United States inflict billions of dollars in damage to homes, businesses, property, and agriculture, with the largest contributor to insured losses being hail (Allen et al. 2017). These losses have been increasing in recent years and were comparable to damage from tropical cyclones (Gunturi and Tippett 2017) until the active 2017 hurricane season.

\footnotetext{
Supplemental information related to this paper is available at the Journals Online website: https://doi.org/10.1175/JAMC-D-180073.s1.
}

Corresponding author: M. Kumjian, kumjian@psu.edu
In part, these increasing losses are due to the relatively frequent occurrence of hailstorms over large portions of the United States, increases in vulnerable property in hail-prone regions, and the increasing value of those properties (e.g., Changnon et al. 2009; Roeder 2012; Giammanco et al. 2015; Brown et al. 2015).

Although the environments that are conducive for severe convective storms capable of producing hail are relatively well understood and anticipated, there is still considerable difficulty in anticipating the severity of the hail risk in terms of hail sizes and damage potential. For example, Blair et al. (2011) found that the U.S. Storm Prediction Center (SPC) severe thunderstorm watches underestimated maximum hail size by nearly a factor of 2 in cases of giant $(>10 \mathrm{~cm})$ hail. Part of the difficulty in 
accurately anticipating the risk from hail is limited knowledge of the main environmental and storm internal controls on hail size. For example, there is no strong correlation between environmental convective available potential energy (CAPE) and hail size (e.g., Edwards and Thompson 1998; Jewell and Brimelow 2009; Johnson and Sugden 2014). Additionally, there is no existing conceptual model for why some storms produce extremely large hail and why others produce large accumulations of small hail. Recent modeling studies have begun tying environmental factors to hail production and storm structural changes. Grant and van den Heever (2014) found that the extent of midtropospheric dryness affects storm structure and hail-growth regions within their simulated storms. Dennis and Kumjian (2017) found significant changes in simulated hail production when environmental wind shear was altered. However, both of these studies are limited by their use of bulk microphysics schemes. Such models are unable to accurately predict hail sizes because large hail is characterized by the tail of a predefined size distribution, which is an oversimplification of real hail size distributions that are poorly constrained by observations.

Further, accurate estimation of hail size from operational radar observations remains a challenge. Prior to the dual-polarization upgrade to the WSR-88D network, National Weather Service (NWS) severe thunderstorm warnings during giant hail cases substantially underestimated maximum hail size; in many cases, warning text indicated $<2.5-\mathrm{cm}$ hail when the storm actually produced hail $>10 \mathrm{~cm}$ in diameter (Blair et al. 2011). Using high-resolution surface observations of hailstones, Blair et al. (2017) found that NWS warnings consistently underestimated maximum hail sizes and were adjusted by incoming reports that also tended to underestimate the maximum sizes in a given storm. Operational radarbased products such as the maximum estimated size of hail (MESH; Witt et al. 1998) have shown little skill in prediction of maximum hail size (Ortega et al. 2009; Cintineo et al. 2012; Ortega 2018).

Indeed, hail size discrimination with only equivalent reflectivity factor at horizontal polarization $Z_{H}$ is difficult if not impossible (Kumjian et al. 2010; Blair et al. 2011; Cintineo et al. 2012; Ortega 2018). More recent work suggests that the use of dual-polarization measurements could improve hail size discrimination. However, operational hail size determination is currently only implemented in coarse hail-size categories (Ryzhkov et al. 2013a,b; Ortega et al. 2016). Although this is an important first step toward hail sizing, improvements can be made. For example, this algorithm does not explicitly use all polarimetric radar variables, notably excluding specific differential phase shift $K_{\mathrm{DP}}$. As we show in this study, $K_{\mathrm{DP}}$ can be useful in identifying cases with large concentrations of small, melting hail. Thus, any improvements to radar-based information about hail size are important for warning decisions and poststorm analyses for insurance claims.

In this study, we focus on storms producing large accumulations of small hail (SPLASH). We define such events as those in which storms produce large concentrations of hail $<2.5 \mathrm{~cm}$ in diameter, which accumulates to the extent that it covers the ground (visually or based on photographs). In extreme SPLASH cases, snowplows have been used to clear the accumulated hail (e.g., Kalina et al. 2016). It is possible that such hail accumulations may arise when heavy rain/floods lead to "hail drifts" in what would otherwise be considered an unremarkable hailstorm. On the other hand, environmental factors may cause hail formation processes in some storms to favor an abundance of smaller stones, which may happen transiently or continuously along a swath. In this study, we provide radar-based evidence of the "formation" paradigm and argue that the storms presented herein are unique in that they produce large concentrations of small, melting hailstones.

Although not as likely to inflict catastrophic damage on homes, businesses, and property as storms producing large hail, SPLASH events can still be disruptive to society. For example, a 2012 Amarillo, Texas, storm created 1-m-tall hail drifts (see Fig. S1 in the online supplemental material) that rendered roadways impassable and led to flooding that washed out roadways (e.g., Scotten et al. 2013). A woman in in El Paso, Texas, died after being swept away by flood waters and buried in accumulating hail in April 2014 (NWS 2014). Other SPLASH events have produced reduced visibility owing to "hail fog" (Ward et al. 2018). There has been recent scientific interest in these types of storms as well (Kalina et al. 2016; Kumjian and Lebo 2016; Ward et al. 2018). Studying such events is in accord with the spirit of the Knight and Knight (2001) summary, in which they suggest all extreme cases of hailstorms (including those that produce only small hail) are "worthy of intense study."

In the following sections, we show that SPLASH events repeatedly exhibit extreme signatures observable in the dual-polarization radar fields, including some that are "off" the operational Advanced Weather Interactive Processing System (AWIPS) color scale. We then show using electromagnetic scattering calculations that large quantities of small melting hail and heavy rain are responsible for the anomalous radar signatures. We also provide an overview of the environmental characteristics of these storms. This study is a first step toward identifying such storms in dual-polarization radar observations and understanding what causes their noteworthy large concentrations of small hail. 


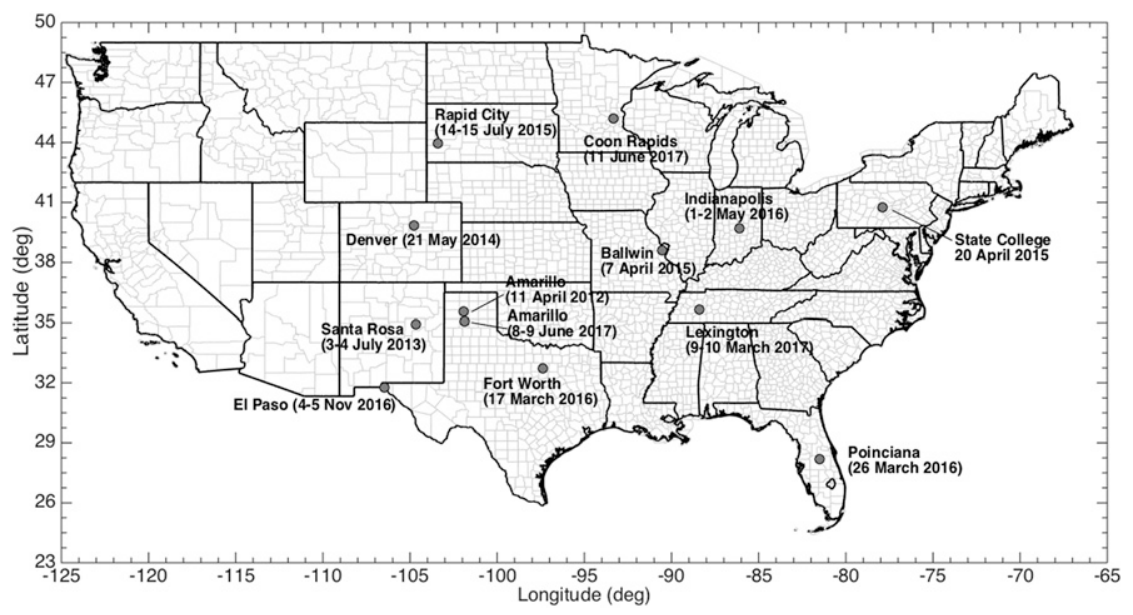

FIG. 1. Map of the contiguous United States showing the locations of each case (gray circle markers), with annotated labels.

\section{Methods and data}

\section{a. Case selection}

The Storm Data database of severe weather reports is not particularly useful for identifying cases of large quantities of small hail, often because these hailstones are below the $2.5-\mathrm{cm}$ diameter threshold for being considered "severe" and are thus not reported or included in the database. As such, we obtain cases based on previously published work, news reports, personal experiences of a SPLASH event, and social media reports. Specifically, cases in which photographs or videos of large amounts of small hail ( $\leq 2.5 \mathrm{~cm}$ as estimated from photographs) at the surface are available were chosen. By large amounts, we mean that the hail was covering the ground. An effort was made to obtain reports from geographically diverse regions (Fig. 1; Table 1 and Table 2). It is clear that this method provides an inherent limitation to our case selection. However, in the absence of a more comprehensive database, we believe this is the best option available for obtaining multiple cases that have different meteorological contexts. Photographs for each case from news reports and social media are included in the online supplemental material (Figs. S1-S13). The photographs we received permission to use do not necessarily reflect the peak accumulations of the events; therefore, some variability in ground cover (owing to melting, plowing, and vehicles driving over the hail) is evident.

\section{b. Radar data}

The nearest WSR-88D instrument to each case was identified, and level-II and level-III data were downloaded from the National Centers for Environmental Information (NCEI) archive. Level-II data at the lowest elevation angles are in $0.5^{\circ}$ azimuthal spacing and $250-\mathrm{m}$ gate spacing, whereas level-III data have been recombined

TABLE 1. List of cases analyzed herein, including the date, time (UTC), and location of each case. In addition, the classified storm mode is given. The presence of radar features including bounded weak-echo regions, three-body scattering signatures, and differential attenuation is noted in the final three columns.

\begin{tabular}{|c|c|c|c|c|c|c|}
\hline Date & Location & Analysis time (UTC) & Storm mode & BWER? & TBSS? & Differential attenuation? \\
\hline 11 Apr 2012 & Amarillo, TX & 2002-2058 & Supercell & Yes & No & Yes \\
\hline 3-4 Jul 2013 & Santa Rosa, NM & $2332-0026$ & Supercell & Yes & Yes & No \\
\hline 21 May 2014 & Denver, $\mathrm{CO}$ & $2000-2055$ & Supercell & Yes & Yes & Yes \\
\hline 7 Apr 2015 & Ballwin, MO & $1403-1456$ & QLCS & No & Yes & Yes \\
\hline 20 Apr 2015 & State College, PA & $2301-2355$ & Supercell & Yes & Yes & Yes \\
\hline $14-15$ Jul 2015 & Rapid City, SD & 0048-0201 & Supercell & Yes & Yes & Yes \\
\hline 17 Mar 2016 & Fort Worth, TX & $1205-1257$ & Supercell & Yes & Yes & Yes \\
\hline 26 Mar 2016 & Poinciana, FL & $2148-2246$ & Supercell & Yes & Yes & Yes \\
\hline 1-2 May 2016 & Indianapolis, IN & 0052-0218 & Supercell & Yes & Yes & Yes \\
\hline 4-5 Nov 2016 & El Paso, TX & $2318-0017$ & Supercell & Yes & Yes & Yes \\
\hline 9-10 Mar 2017 & Lexington, TN & 0330-0430 & QLCS & No & Yes & Yes \\
\hline 9 Jun 2017 & Amarillo & 0124-0215 & Supercell & Yes & Yes & Yes \\
\hline 11 Jun 2017 & Coon Rapids, MN & $1304-1356$ & QLCS & No & No & Yes \\
\hline
\end{tabular}


TABLE 2. Maximum hail size reported during the analysis time for each case (obtained from the SPC), as well as relevant notes or comments contained in the SPC information $(1 \mathrm{in} .=2.54 \mathrm{~cm})$.

\begin{tabular}{|c|c|c|}
\hline Case & Max hail size reported (in.) & Notes \\
\hline Amarillo (2012) & 1.0 & \\
\hline Santa Rosa & 1.75 & \\
\hline Denver & 1 & \\
\hline Ballwin & 1.75 & Early in the analysis period; max size in Ballwin is 1 in. \\
\hline State College & 1 & \\
\hline Rapid City & 1.25 & "Mostly pea size 3-5 inches deep. A few larger stones to half dollar size." \\
\hline Fort Worth & 2.5 & \\
\hline Poinciana & 1.5 & Early in the analysis period; 1 -in. max size in Poinciana \\
\hline Indianapolis & 2 & Only 1 in. reported in Indianapolis \\
\hline El Paso & 1 & \\
\hline Lexington & 2.5 & $\begin{array}{l}\text { "Two rounds of hail ended up leaving } 2 \text { to } 3 \text { inch depth over roads in } \\
\text { Lexington..." (associated with a } 1 \text {-in. report) }\end{array}$ \\
\hline Amarillo (2017) & 2.5 & $\begin{array}{l}\text { " } 6-8 \text { inches of hail covering both sides of Washington..." (associated with } \\
\text { a } 1 \text {-in. report) }\end{array}$ \\
\hline Coon Rapids & 1.75 & \\
\hline
\end{tabular}

to $1.0^{\circ}$ and $250-\mathrm{m}$ spacing. Level-III data closely emulate the radar data available to operational National Weather Service meteorologists, whereas level-II data include higher tilts and the data for raw propagation differential phase $\Phi_{\mathrm{DP}}$. The latter is important for $K_{\mathrm{DP}}$ estimation. For a primer on the physical meaning of dual-polarization radar variables and their applications, see reviews by Zrnić and Ryzhkov (1999), Ryzhkov et al. (2005), Kumjian (2013a,b,c, 2018), and Chandrasekar et al. (2013).

\section{c. Scattering calculations}

To test the hypothesis that the observed anomalous radar signatures are caused by large amounts of small melting hail and to explore the possible particle sizes and concentrations responsible for the observed radar signatures, we use the two-layer T-matrix method originally from Bringi and Seliga (1977a,b) for electromagnetic scattering calculations. These calculations produce simulated S-band ( $\sim 11-\mathrm{cm}$ wavelength) dual-polarization radar variables for spheroidal particles of various sizes and aspect ratios. We use two-layer spheroids to represent small melting hail: the particles have an outer shell with relative permittivity equal to that of liquid water at $0^{\circ} \mathrm{C}$ and an inner core with relative permittivity equal to that of solid ice at $0^{\circ} \mathrm{C}$. Other assumptions regarding the distribution of liquid water within the particle (e.g., uniformly distribute liquid throughout the particle) generally will lead to reduced polarimetric contrasts, ceteris paribus [e.g., see Kumjian et al. (2012) and Ryzhkov et al. (2013a,b)]. The hailstones are assumed to carry their maximum allowable liquid water mass, which is a function of size following Rasmussen and Heymsfield (1987), Ryzhkov et al. (2013a), and Kumjian et al. (2018). Because the extreme radar signatures reported herein are found in the lowest levels, assuming the maximum allowable liquid meltwater mass is reasonable. Together, these assumptions will maximize the polarimetric contrasts and thus can be considered the upper limit for the resulting enhancements in the polarimetric radar variables. These calculations are similar to those performed in numerous studies (e.g., Jung et al. 2010; Snyder et al. 2010; Ryzhkov et al. 2011, 2013a,b; Kumjian et al. 2014, 2018). Additional details about the assumptions used for these calculations can be found in Kumjian et al. (2018).

\section{d. Environmental information}

Given the lack of proximity soundings for most of the cases, we use data from the Rapid Refresh model (RAP; Benjamin et al. 2016, formerly known as the Rapid Update Cycle or RUC model) to characterize the mesoscale environment in which these storms develop. RAP data were obtained from the NCEI archive. Specifically, we use 1-h forecasts (to mitigate potential biases in model initialization fields caused by input of erroneous surface observations) that are valid 1 or $2 \mathrm{~h}$ before the SPLASH event. These times were chosen to avoid any contamination from convection ongoing in the model simulations; model output fields were manually examined to ensure that high $[>40 \mathrm{dBZ}$ (sometimes written dBz; Smith 2010)] simulated composite reflectivity values were not present at the location of the hail event. Distributions of environmental parameters (CAPE, shear, etc.) surrounding the hail event location were obtained from the RAP-model output. This includes \pm 5 grid boxes in all directions from the event location for the $\sim 13-\mathrm{km}$ RAP output, and \pm 3 grid boxes for the $\sim 20$-km RAP output. The differing resolutions are a result of operational changes made to the RAP/RUC during the several-year period from which cases were selected. This results in values from 121 grid points included for the $13-\mathrm{km}$ RAP 

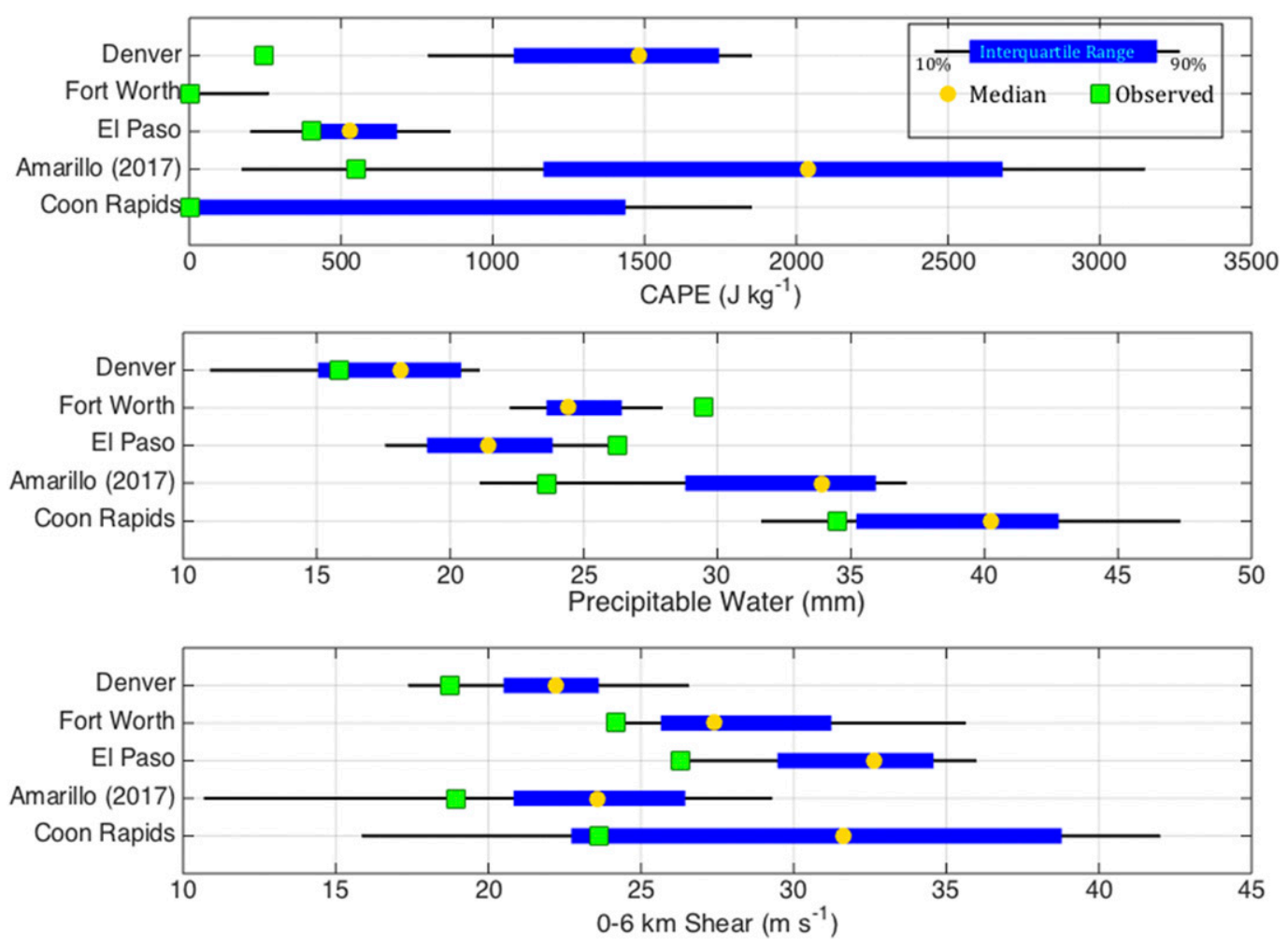

FIG. 2. Distribution of sounding-derived quantities from the RAP model (box-and-whisker plots: blue is the interquartile range, whiskers show $10 \%-90 \%$, and the gold circle is the median) and the observed sounding quantity (green square marker) for (top) surface-based CAPE, (middle) PWAT, and (bottom) 0-6-km shear. These results are from the soundings shown in supplemental Figs. S14-S18.

output and 49 grid points included for the 20-km RAP output. Despite the differing number of grid points included in the analyses, the geographical area encompassed is roughly the same. This area was selected to approximately capture the mesoscale variability of the storm's environment.

How well do the RAP analyses capture the environment? For five of the cases (Denver, Colorado; Fort Worth, Texas; El Paso, Texas; Amarillo, Texas, in 2017; and Coon Rapids, Minnesota) there are observed operational rawinsondes that are valid within $2 \mathrm{~h}$ of the RAP analysis time and within $100 \mathrm{~km}$ of the hail report location, which we deem sufficiently matched in space and time to evaluate the RAP performance. For these cases, we compared the observed sounding profiles to those generated from the RAP composite of grid boxes around the sounding location. In addition, we compared the distribution of RAP-analyzed important parameters (CAPE, precipitable water, and 0-6-km shear) with those computed from the five observed soundings. These comparisons are provided in the online supplemental materials (Figs. S14-S18). These comparisons reveal that the temperature profiles are quite consistent between the RAP composite and the observed sounding, especially given that the RAP analyses are averages over an $\sim 100 \mathrm{~km} \times 100 \mathrm{~km}$ area (and thus some features are smoothed relative to the observed soundings). Additional minor differences (especially at low levels) are consistent with time offsets and the diurnal cycle (e.g., the later profile shows additional warming, etc.). The dewpoint temperatures show more discrepancies, especially aloft, which is expected to most significantly affect the precipitable water. Finally, surface-to-100-hPa hodograph shapes are broadly consistent between the RAP composites and observed soundings, though the details are often smoothed out in the RAP composite. One notable discrepancy is in the Coon Rapids hodograph, in which the observed profile aloft ( $>10 \mathrm{~km}$ AGL) exhibits much greater zonal winds than the composite RAP hodograph. Comparing the distributions of sounding-derived quantities (Fig. 2), one finds that the observed sounding parameters generally fall within the RAP distributions, with the exceptions of CAPE for the Denver case (the RAP distribution has much larger values, although note that the analysis is valid an hour later in the afternoon) and precipitable water for the Fort Worth case (the RAP distribution underestimates values). Despite the challenges with the lack of proximity soundings and the 
discrepancies noted in the five proximity soundings used to verify the RAP model, these composite analyses are deemed sufficient for characterizing the environments of the SPLASH cases.

\section{Radar analysis}

\section{a. Storm structural features}

Plan position indicators (PPIs) of level-III $Z_{H}$ at low levels (Figs. 3 and 4 ) reveal a variety of storm structures among the 13 cases, although with some commonalities. All have regions of $Z_{H}$ values of $>60 \mathrm{~dB} Z$ in the lowest elevation angle scan at some point in their lifetimes, with maximum values in all but two of the cases (Ballwin, Missouri; Coon Rapids, Minnesota) at times exceeding $70 \mathrm{~dB} Z$; the two cases that did not achieve $70 \mathrm{~dB} Z$ had $Z_{H}$ maxima of $>65 \mathrm{~dB} Z$.

Ten of the storms are classified as supercells (Table 1), with typical supercellular structures including cyclonic shear evident in radial velocities at midlevels (not shown), and hooklike appendages in the low-level $Z_{H}$ scans (e.g., Figs. 3a,c,f and 4i,j). The remaining three cases (Ballwin, Missouri; Lexington, Tennessee; Coon Rapids, Minnesota) are classified as quasi-linear convective systems (QLCS). All but two cases featured prominent three-body scattering signatures (TBSS; Zrnić 1987) aloft and occasionally at low levels (e.g., Fig. 3b; see also Table 1), and 10 cases (all supercells) exhibited pronounced bounded weak-echo regions (BWER) aloft (not shown; see Table 1). TBSSs are indicative of considerable amounts of radiation being scattered from the precipitation core, which could mean the presence of large hailstones or large concentrations of smaller hailstones (i.e., the hail size information contained in TBSSs is ambiguous; e.g., Zrnić et al. 2010; Kumjian 2013c). BWERs are indicative of strong updrafts capable of hail production.

A more striking feature is found in the polarimetric radar fields of all but one case (Santa Rosa, New Mexico, is the exception): anomalously large $K_{\mathrm{DP}}$. Here, we define "anomalously large" as $K_{\mathrm{DP}}$ values of $>7.5^{\circ} \mathrm{km}^{-1}$, substantially in excess of what is typical or expected in convective storms. For example, $K_{\mathrm{DP}}$ is not expected to exceed $5^{\circ}-6^{\circ} \mathrm{km}^{-1}$ in heavy convective rain (e.g., Kumjian 2013a; Morrison et al. 2019; Kumjian et al. 2019). For storms that produce large hail, the classic low- $Z_{\mathrm{DR}}$ hail signature (e.g., Aydin et al. 1986; Wakimoto and Bringi 1988 ) is typically not associated with large $K_{\mathrm{DP}}$ values, either (Kumjian 2013b). Even the level-III data and operational color tables for $K_{\mathrm{DP}}$ only allow values up to $10.7^{\circ} \mathrm{km}^{-1}$ because values this large are not expected in typical precipitation. Thus, $K_{\mathrm{DP}}$ values approaching or exceeding this upper limit are noteworthy.

Figures 5 and 6 show zoomed-in snapshots of the same storms and times as in Figs. 3 and 4. Note that some storms had persistently high $K_{\mathrm{DP}}$ for numerous scans as discussed later; the examples in Figs. 5 and 6 were chosen to be illustrative at particularly extreme times, though each occurs within $\pm 30 \mathrm{~min}$ of when the storm was over the location of the photographs (Figs. S1-13) as indicated by a yellow circle marker, when applicable. Eight of the cases had maximum level-III $K_{\mathrm{DP}}$ values of $>10^{\circ} \mathrm{km}^{-1}$, including Figs. 5a,d,g and $6 \mathrm{i}, \mathrm{k}, 1, \mathrm{~m}$. All but one of the remaining five cases had maximum values of $>8^{\circ} \mathrm{km}^{-1}$ (Figs. 5c,e,f and 6h,j). As explained in the following section, such extreme $K_{\mathrm{DP}}$ values are suggestive of large mass contents of nonspherical hydrometeors. The only "null case" in those analyzed here is that of Santa Rosa (Fig. 5b), which exhibited near-zero $K_{\mathrm{DP}}$ throughout the storm at the altitude sampled by the radar in this PPI $(\sim 1.5 \mathrm{~km}$ above radar level). This may be attributable to very dry lower-tropospheric conditions: dewpoint depressions were entirely greater than $13^{\circ} \mathrm{C}$ in the lowest $\sim 3.5 \mathrm{~km}$ AGL as observed by the 0000 UTC 4 July 2013 Albuquerque, New Mexico, sounding, and averaged $>18^{\circ} \mathrm{C}$ in the lowest $1.5 \mathrm{~km}$ AGL. Such a dry lower troposphere inhibits melting and facilitates evaporation of raindrops. Small, drier hail is not expected to produce substantial $K_{\mathrm{DP}}$ (e.g., Kumjian 2013a; Ryzhkov et al. 2013a,b).

All but one case (Santa Rosa; see Table 1) also exhibited differential attenuation, evident as severe negative $Z_{\mathrm{DR}}$ biases downrange of the high- $Z_{H}$, high- $K_{\mathrm{DP}}$ hail cores. Such differential attenuation is not expected at $\mathrm{S}$ band (e.g., Ryzhkov et al. 2013b). Figure 7 shows four illustrative examples of negative $Z_{\mathrm{DR}}$ swaths emanating from the rear of the storm. Although TBSSs often produce negative $Z_{\mathrm{DR}}$ values behind hail cores (e.g., Hubbert and Bringi 2000; Picca and Ryzhkov 2012; Kumjian 2013c), the negative $Z_{\mathrm{DR}}$ swaths in these cases extended much farther downrange than is typical of low-level TBSSs, and broaden in range (indicating it is a propagation, not scattering, effect). Further, the extremely weak $Z_{H}$ expected from TBSSs at such large ranges (Zrnić 1987) is easily masked by downrange precipitation echoes. Last, collocated attenuation of the signal is evident in the $Z_{H}$ field of the Indianapolis, Indiana, case (not shown), which also strongly suggests that differential attenuation is occurring. It is plausible, however, that nonuniform beam filling (NBF) also contributed to the negative $Z_{\mathrm{DR}}$ biases (Ryzhkov 2007). Nevertheless, there is reason to believe that regions of high $K_{\mathrm{DP}}$ and large specific differential attenuation $A_{\mathrm{DP}}$ are often collocated based on scattering theory and the calculations discussed in the following section.

There are several limitations of the level-III $K_{\mathrm{DP}}$ data shown so far. The observations show that $K_{\mathrm{DP}}$ often "saturated" at the maximum allowable value $\left(10.7^{\circ} \mathrm{km}^{-1}\right)$. When the copolar correlation coefficient $\rho_{\text {hv }}$ drops below 0.90 , level-III $K_{\mathrm{DP}}$ values are censored 

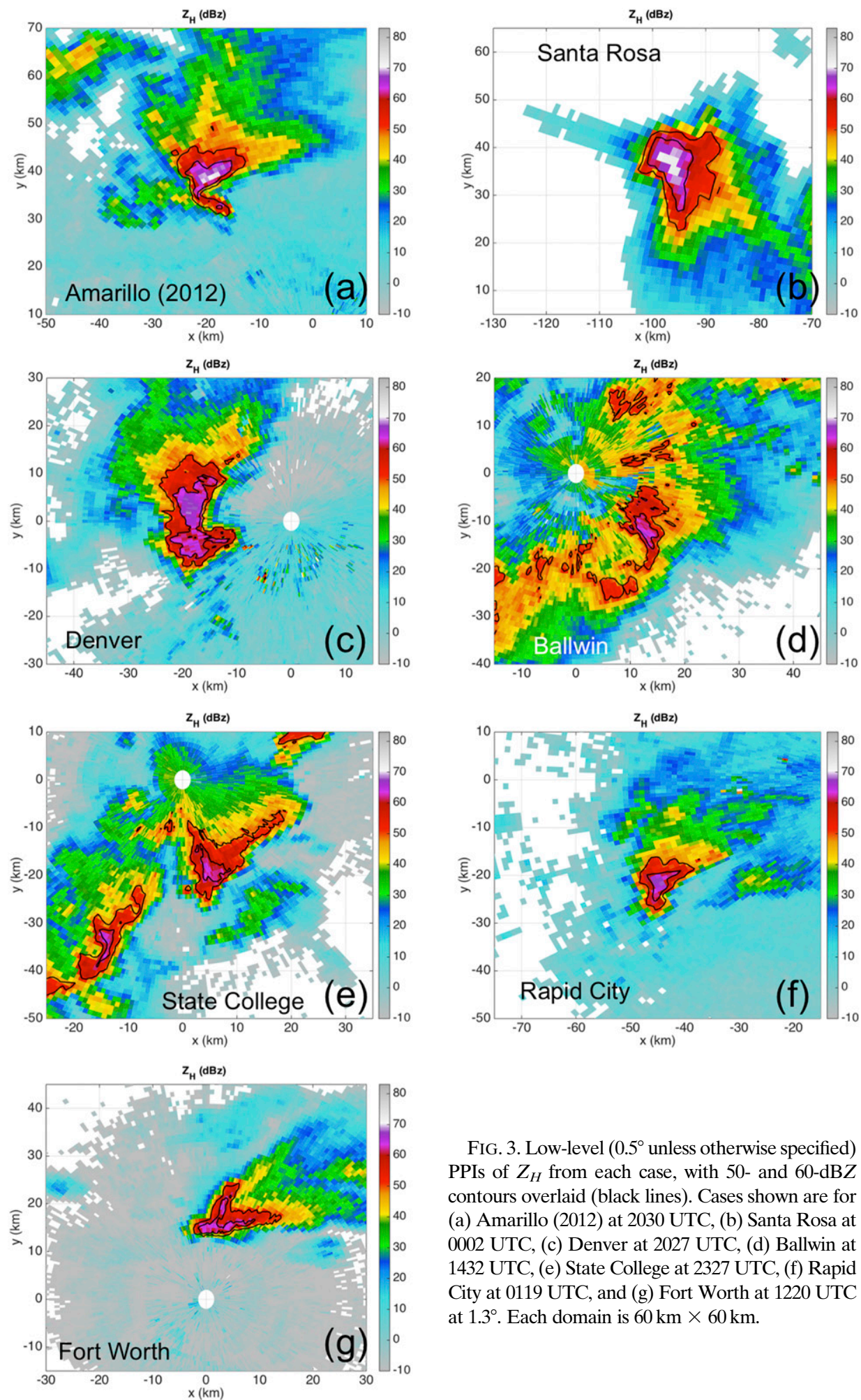

FIG. 3. Low-level ( $0.5^{\circ}$ unless otherwise specified) PPIs of $Z_{H}$ from each case, with 50- and 60-dBZ contours overlaid (black lines). Cases shown are for (a) Amarillo (2012) at 2030 UTC, (b) Santa Rosa at 0002 UTC, (c) Denver at 2027 UTC, (d) Ballwin at 1432 UTC, (e) State College at 2327 UTC, (f) Rapid City at 0119 UTC, and (g) Fort Worth at 1220 UTC at $1.3^{\circ}$. Each domain is $60 \mathrm{~km} \times 60 \mathrm{~km}$. 

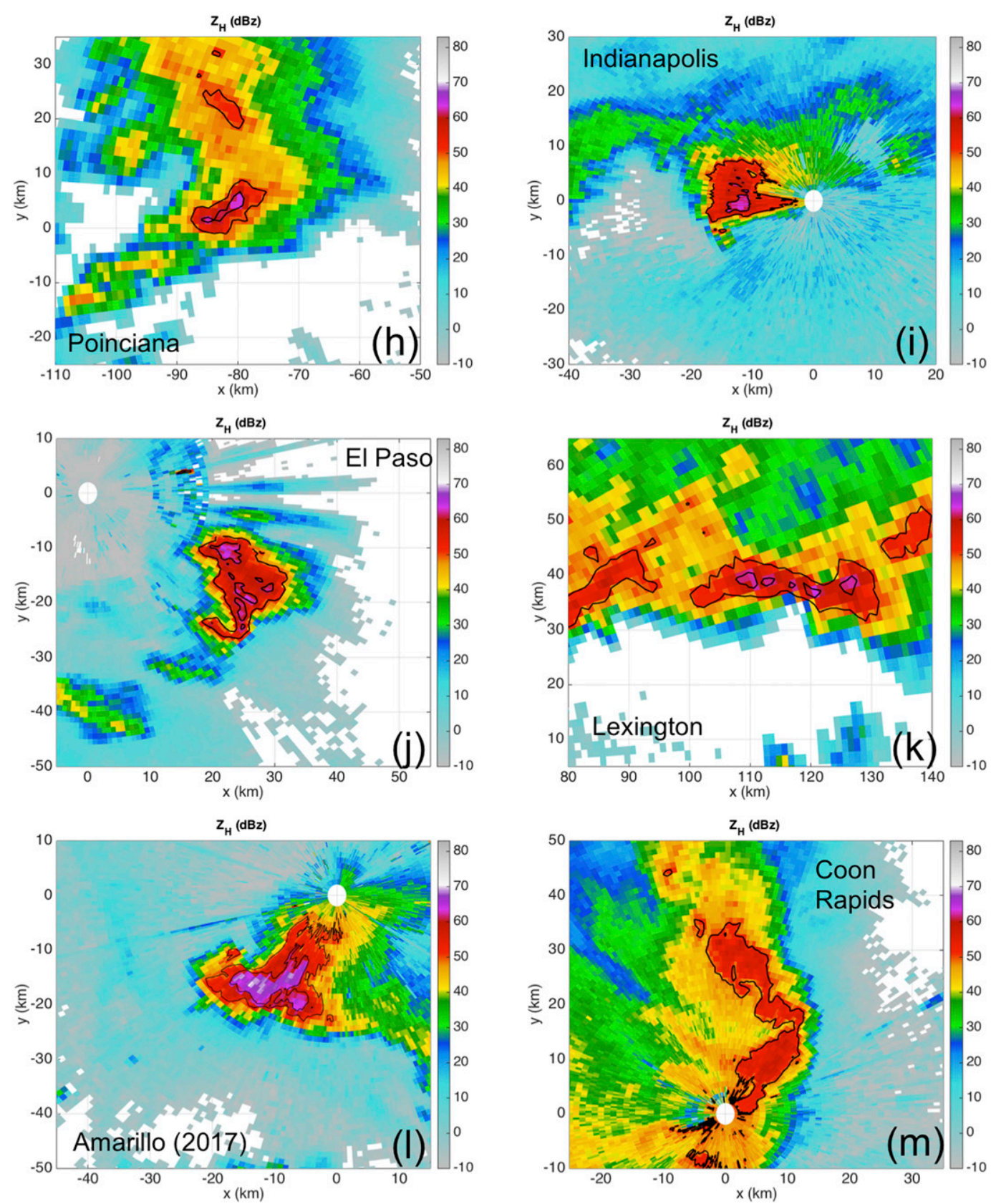

FIG. 4. As in Fig. 3, but for (h) Poinciana (Florida) at 2219 UTC; (i) Indianapolis at 0110 UTC at 1.3; (j) El Paso at 2349 UTC; (k) Lexington at 0403 UTC; (1) Amarillo (2017) at 0158 UTC; and (m) Coon Rapids at 1337 UTC. Each domain is $60 \mathrm{~km} \times 60 \mathrm{~km}$.

(e.g., Kumjian 2013a,b). This occurs frequently in severe convective storms, often as a result of NBF (e.g., Figs. 5a,f,g and $6 \mathrm{k}$ ). Thus, in some cases, censored $K_{\mathrm{DP}}$ pixels belie the true underlying $\Phi_{\mathrm{DP}}$ trends. Given these issues with level-III data, it is of interest to determine exactly how high $K_{\mathrm{DP}}$ is in these storms, which can be helpful when comparing the observations with the scattering calculations presented in section 4 .
To get a better estimate of the $K_{\mathrm{DP}}$ values in these extreme storms, we use the raw level-II $\Phi_{\mathrm{DP}}$ data. The raw $\Phi_{\mathrm{DP}}$ data can be extremely noisy, especially in regions of reduced $\rho_{\mathrm{hv}}$. As a first pass to clean up the data, any large spikes in $\Phi_{\mathrm{DP}}$ (single points) along the radial were replaced with the average of values in adjacent gates. Larger segments of noisy or missing values (i.e., more than one range gate) were removed and a 

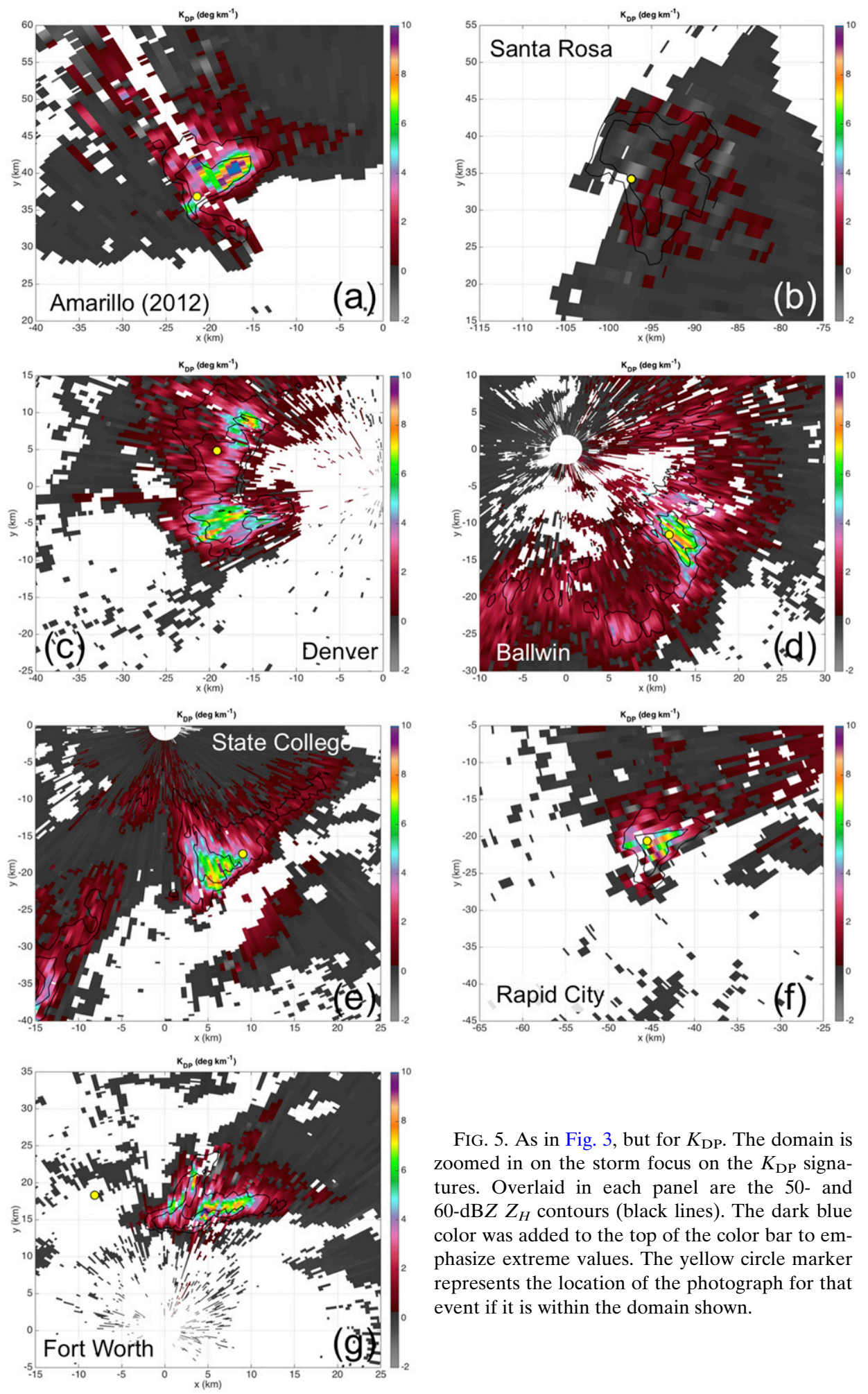

FIG. 5. As in Fig. 3, but for $K_{\text {DP. }}$ The domain is zoomed in on the storm focus on the $K_{\mathrm{DP}}$ signatures. Overlaid in each panel are the 50- and 60-dBZ $Z_{H}$ contours (black lines). The dark blue color was added to the top of the color bar to emphasize extreme values. The yellow circle marker represents the location of the photograph for that event if it is within the domain shown. 

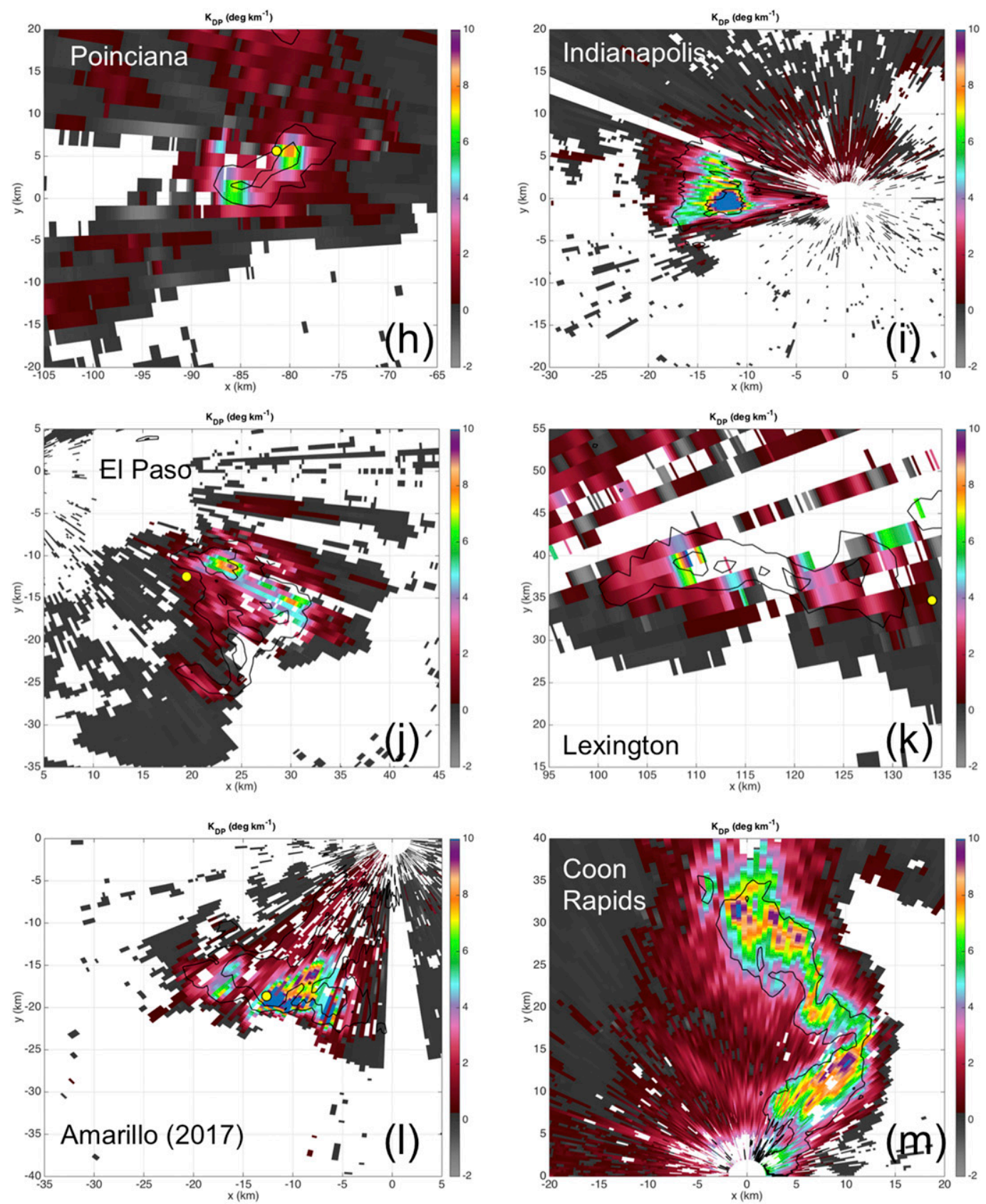

FIG. 6. As in Fig. 4, but for low-level $K_{\mathrm{DP}}$, with $Z_{H}$ contours overlaid.

linear interpolation was performed from the nearest gates on either side. After these cleaning procedures, radial profiles of $\Phi_{\mathrm{DP}}$ shown herein were manually inspected to ensure data quality. Once $\Phi_{\mathrm{DP}}$ profiles were sufficiently free of erroneous or missing data points, $K_{\mathrm{DP}}$ estimation was performed. There are a variety of techniques used for $K_{\mathrm{DP}}$ calculations in the literature (Hubbert and Bringi 1995; Ryzhkov et al. 2005; Wang and Chandrasekar 2009; Giangrande et al. 2013). Like
Kalina et al. (2016), here we also apply the finite impulse response filter of Hubbert and Bringi (1995) to smooth the $\Phi_{\mathrm{DP}}$ data. After smoothing, the linear fit of the data in a five-gate $(1.25 \mathrm{~km})$ moving window was calculated; $K_{\mathrm{DP}}$ is one-half of this line's slope.

Figures 8 and 9 show the edited and smoothed $\Phi_{\mathrm{DP}}$ data and corresponding $K_{\mathrm{DP}}$ estimates for the 2017 Amarillo and Indianapolis cases, respectively, along several radials that produced some of the largest $\Phi_{\mathrm{DP}}$ accumulations. 

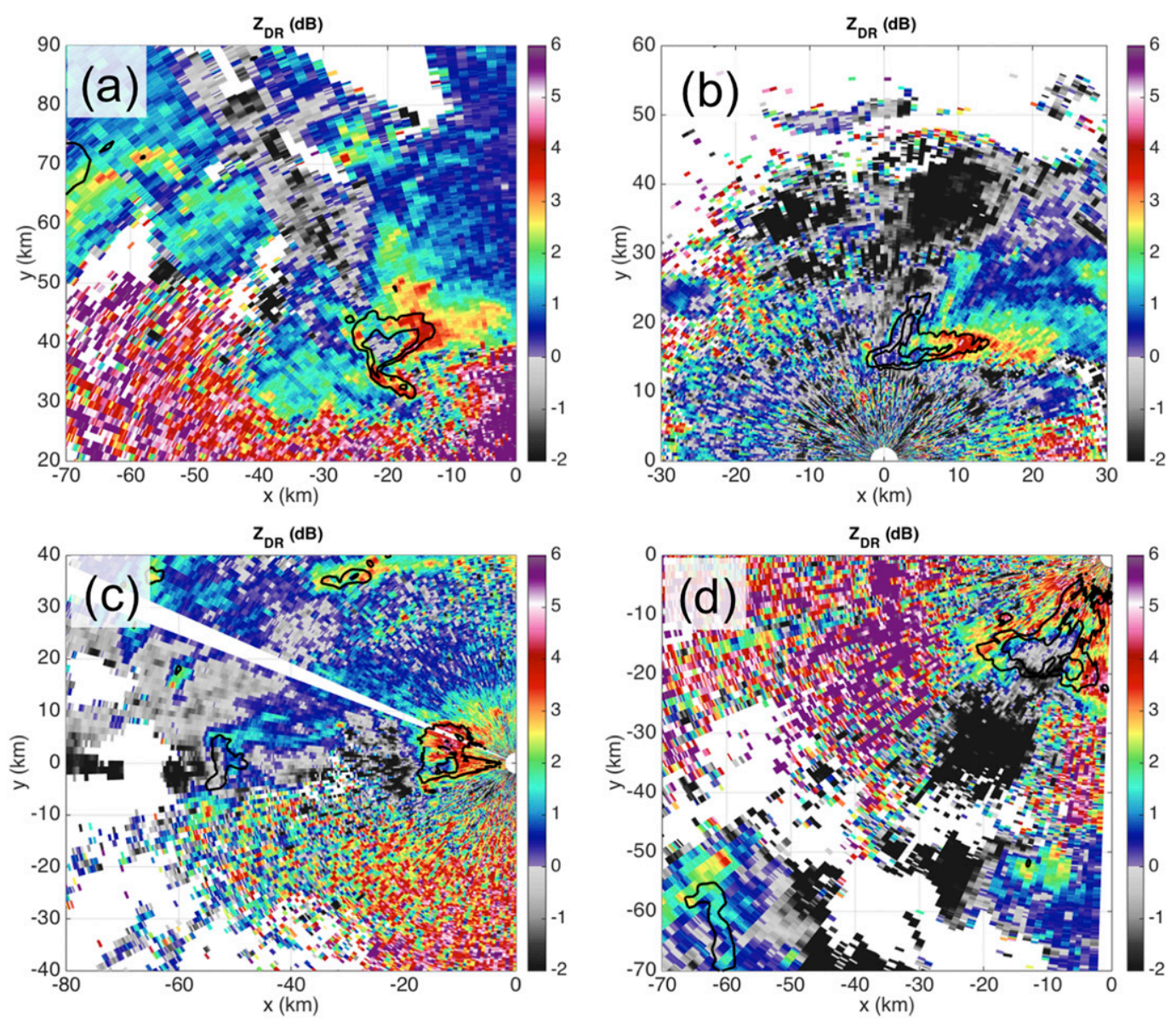

FIG. 7. Example low-level PPIs of $Z_{\mathrm{DR}}$ from four cases showing significant differential attenuation: (a) Amarillo (2012) (storm centroid is roughly $x=-20 \mathrm{~km}, y=40 \mathrm{~km}$ ), (b) Fort Worth (storm centroid is roughly $x=0 \mathrm{~km}, y=$ $15 \mathrm{~km}$ ), (c) Indianapolis (storm centroid is roughly $x=-15 \mathrm{~km}, y=-2 \mathrm{~km}$ ), and (d) Amarillo (2017) (storm centroid is roughly at $x=-15 \mathrm{~km}, y=-20 \mathrm{~km}$ ). Overlaid are the 50 - and $60-\mathrm{dB} Z$ contours of $Z_{H}$.

Maximum $K_{\mathrm{DP}}$ values in Fig. 8 are greater than $10^{\circ} \mathrm{km}^{-1}$, with the largest peaking at $\sim 13.2^{\circ} \mathrm{km}^{-1}$. In Fig. 9, several radials feature $K_{\mathrm{DP}}$ values between $10^{\circ}$ and $15^{\circ} \mathrm{km}^{-1}$; maximum values are $17.6^{\circ}$ and $17.1^{\circ} \mathrm{km}^{-1}$. To our knowledge, these are the largest values recorded at $\mathrm{S}$ band in precipitation. For perspective, if expressed in terms of rainfall rate using the $R\left(K_{\mathrm{DP}}\right)$ relationship from Giangrande and Ryzhkov (2008), this maximum value corresponds to $464 \mathrm{~mm} \mathrm{~h}^{-1}$ ! Such large $K_{\mathrm{DP}}$ values clearly indicate the presence of large concentrations of nonspherical, wet particles such as large raindrops and/or small melting hailstones. We argue that these extreme $K_{\mathrm{DP}}$ values are the hallmark of large concentrations of small melting hail. In the next section, we outline the physical basis for this hypothesis, and test it using scattering calculations.

\section{b. Storm-tracking analysis}

Kalina et al. (2016) report slow storm translation speeds $\left(6-9 \mathrm{~m} \mathrm{~s}^{-1}\right)$ in their four SPLASH cases from
Colorado. They argued that such slow storm motions aided in the large accumulations observed in each case. It is of interest here to determine how the storm translation speeds from the 13 SPLASH cases analyzed herein compare to those studied by Kalina et al. (2016). To estimate storm motion, we first found radar gates in lowelevation-angle PPIs (see Figs. 3, 4) with $Z_{H}$ values in excess of different thresholds $(>50,>60$, and $>70 \mathrm{dBZ}$ ) associated with each storm. The $x$ and $y$ coordinates (relative to the radar) of each of these gates are determined, and the median location (centroid) of these enhancement regions is computed. These centroids were tracked for consecutive scans over approximately a 1-h analysis period (see times in Table 1) centered on the time shown in Figs. 3 and 4. A least squares regression line was fit to the centroid positions over this analysis period to determine the storm motion and direction following Loeffler and Kumjian (2018). The distribution of storm motions estimated from this tracking algorithm applied to the 

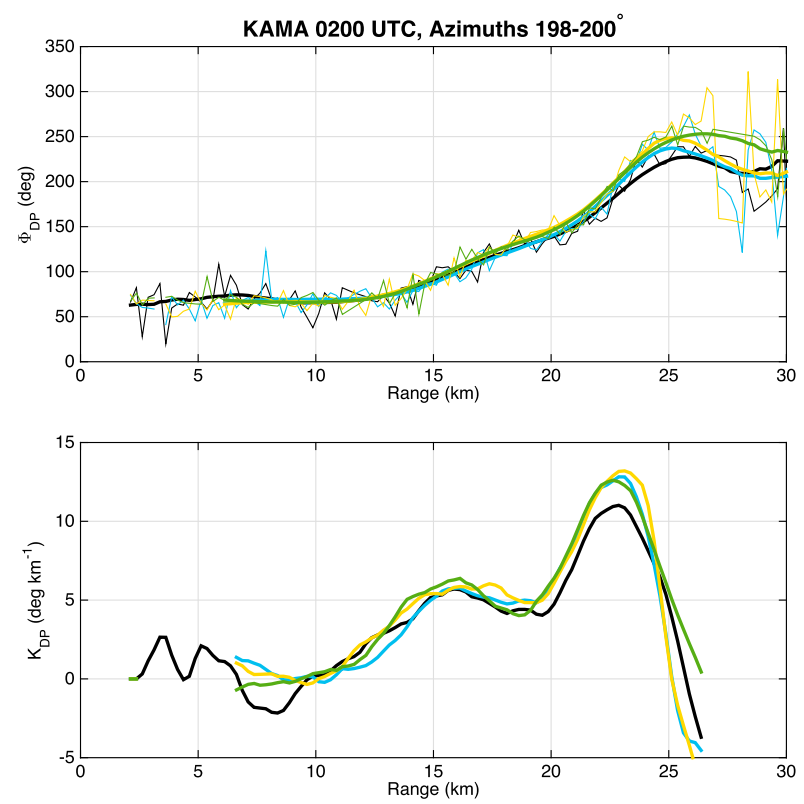

FIG. 8. (top) Selected range profiles of the raw $\Phi_{\mathrm{DP}}\left({ }^{\circ}\right.$; thin colored lines) from the Amarillo (2017) case. Overlaid are the filtered profiles (thick colored lines). (bottom) Estimated $K_{\mathrm{DP}}\left({ }^{\circ} \mathrm{km}^{-1}\right)$ as a function of range for each of the profiles in the top panel. Data are from $0200 \mathrm{UTC}$, including azimuths from $198^{\circ}$ to $200^{\circ}$. The different colors correspond to different azimuths and have no other meaning. The peak $K_{\mathrm{DP}}$ values correspond to heights between about 200 and $300 \mathrm{~m}$ above radar level, corresponding to temperatures of approximately $301 \mathrm{~K}$.

60-dBZ centroid is shown in Fig. 10. The cases exhibited a larger variation in storm motions than the four cases reported in Kalina et al. (2016). Notably, $61.5 \%$ of the storms analyzed herein had translation speeds that were greater than those in Kalina et al. (2016), with an average of about $11.3 \mathrm{~m} \mathrm{~s}^{-1}$. Although there is no question that slower storm motions could enhance the small hail accumulations as suggested by Kalina et al. (2016), it does not appear to be a necessary condition for such accumulations. Recent work by Wallace et al. (2018) also seems to support the notion that storm translation speed is not a strong predictor of hail accumulation.

We also used this tracking algorithm to identify enhanced- $K_{\mathrm{DP}}$ regions $\left(>5,>7.5\right.$, and $\left.>10^{\circ} \mathrm{km}^{-1}\right)$. From the range of these gates and those of the high- $Z_{H}$ regions, we calculated the area occupied by these $K_{\mathrm{DP}}$ and $Z_{H}$ enhancements and tracked them over the analysis period. The time series for each of the 13 cases are shown in Fig. 11. Areas of gates with $Z_{H}>60 \mathrm{~dB} Z$ tend to be less than $100-200 \mathrm{~km}^{2}$, suggesting relatively compact storm structures. Regions of $Z_{H}>70 \mathrm{~dB} Z$, if they exist, rarely exceed $10-20 \mathrm{~km}^{2}$ in area. The areas of $K_{\mathrm{DP}}>5^{\circ} \mathrm{km}^{-1}$ tend to be between 10 and $100 \mathrm{~km}^{2}$ for all cases, whereas $K_{\mathrm{DP}}>$ $7.5^{\circ} \mathrm{km}^{-1}$ only exceeds $10 \mathrm{~km}^{2}$ for about one-half of
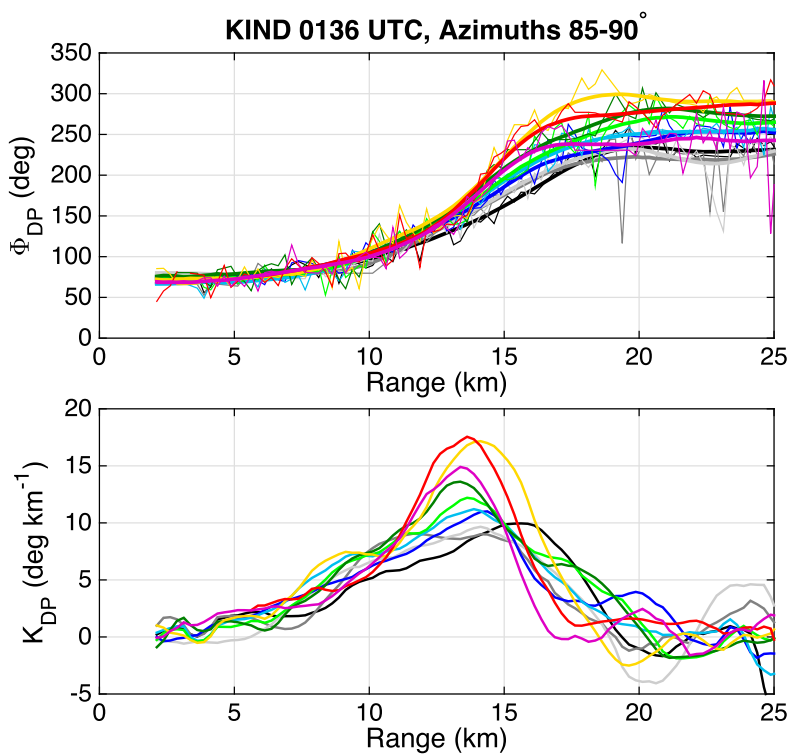

FIG. 9. As in Fig. 8, but for the Indianapolis case. Data are from 0136 UTC, including azimuths $85^{\circ}-90^{\circ}$. The peak $K_{\mathrm{DP}}$ values correspond to heights between approximately 250 and $375 \mathrm{~m}$ above radar level, corresponding to temperatures of about $293 \mathrm{~K}$.

the cases (Amarillo, Texas, in 2012; Rapid City, South Dakota; State College, Pennsylvania; Amarillo in 2017; Indianapolis, Indiana; Lexington, Tennessee; Coon Rapids, Minnesota). Regions of $K_{\mathrm{DP}}>10^{\circ} \mathrm{km}^{-1}$ occur in eight cases. Note the transient decrease in these enhanced- $K_{\mathrm{DP}}$ areas for Indianapolis and Amarillo (2017) are an artifact of the storms passing through the radar cone of silence. Aside from this artifact, these two cases have remarkably consistent periods of substantial areas of $>10^{\circ} \mathrm{km}^{-1} K_{\mathrm{DP}}$; these two cases also exhibited the largest $K_{\mathrm{DP}}$ values, as shown above. For all cases except Indianapolis, Lexington, and Coon Rapids, the $60-\mathrm{dB} Z$ area tends to be greater than or equal to the $5^{\circ} \mathrm{km}^{-1} K_{\mathrm{DP}}$ area for the majority of the time series. Even for these three exceptions, the areas differ by less than an order of magnitude. Overall, the impression is that the high- $K_{\mathrm{DP}}$ phenomenon is more of a continuous or intermittent process as opposed to a single transient event. This is especially true when viewing the Indianapolis and Amarillo (2017) cases.

For each of the time series, we quantified the joint occurrence of enhanced $Z_{H}$ and $K_{\mathrm{DP}}$ pixels by binning the data into $1 \mathrm{~dB} \times 0.5^{\circ} \mathrm{km}^{-1}$ bins and counting the occurrences across all 13 cases. The joint histogram is shown in Fig. 12. The bulk of the $K_{\mathrm{DP}}>8^{\circ} \mathrm{km}^{-1}$ points occurs for $Z_{H}>55 \mathrm{~dB} Z$, as expected. In addition, most of the extreme $K_{\mathrm{DP}}\left(>10^{\circ} \mathrm{km}^{-1}\right)$ points occur for $Z_{H}>$ $55 \mathrm{~dB} Z$, as well, with the mode for such high- $K_{\mathrm{DP}}$ points occurring between 60 and $65 \mathrm{~dB} Z$. Note the extreme $K_{\mathrm{DP}}$ values with low counts for $Z_{H}<50 \mathrm{~dB} Z$ are likely bad $K_{\mathrm{DP}}$ estimates. The fact that large $K_{\mathrm{DP}}$ values can 


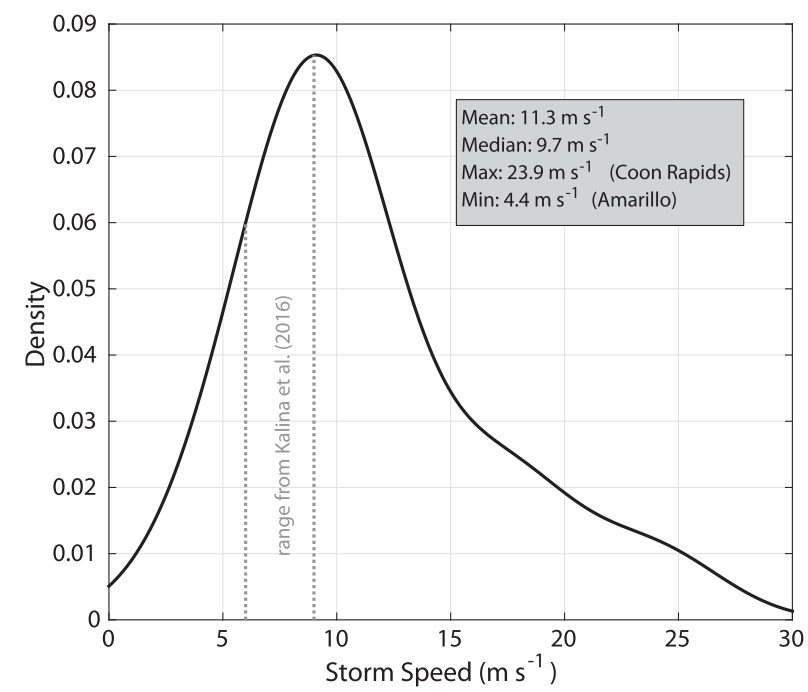

FIG. 10. Kernel density estimate of the distribution of storm motions estimated from radar observations. Statistics are shown in the inset gray-shaded box. The range of storm motions observed in Kalina et al. (2016) is annotated. A bandwidth of $5 \mathrm{~m} \mathrm{~s}^{-1}$ was used for the kernel density estimation.

occur across a range of $Z_{H}$ values implies that different sizes (and thus concentrations) of small melting hail may contribute to the observed signatures. In the next section, we investigate the contributions of melting hail of different sizes to the overall $Z_{H}$ and $K_{\mathrm{DP}}$ using electromagnetic scattering calculations.

\section{Interpretation of the anomalous $K_{\mathrm{DP}}$ values}

\section{a. Physical interpretation of $K_{\mathrm{DP}}$}

By definition, $K_{\mathrm{DP}}$ is one-half of the range derivative of the propagation differential phase shift, $\Phi_{\mathrm{DP}}$. In turn, $\Phi_{\mathrm{DP}}$ is the measured difference in phase of the forwardpropagating radar waves at horizontal polarization and vertical polarization. This phase difference arises owing to the waves propagating through an anisotropic medium, such as nonspherical precipitation particles like raindrops or small melting hailstones. Physically, the propagating wave that is measured or experienced by particles downrange is the sum of the incident radar wave and the wave forward scattered from the collection of particles uprange. Bohren and Huffman (1983) show that the forward-scattered wave from a slab of dielectric particles (with refractive index $n>$ 1) has a $90^{\circ}$ phase lag relative to the incident wave, plus any phase shift acquired on scattering. The total (forward propagating) wave then has a phase lag relative to a freely propagating wave. The greater the $\operatorname{size}^{1}$ and/or

\footnotetext{
${ }^{1}$ Within the range of sizes over which the Rayleigh approximation to scattering is valid.
}

concentration of particles is, the greater is the contribution of the forward-scattered wave to the summation and, thus, the greater is the phase shift relative to the freely propagating wave. The phase shifts can be different at horizontal and vertical polarizations owing to the near-field interactions that characterize nonspherical particles - the same near-field interactions that lead to nonzero $Z_{\mathrm{DR}}$ (Kumjian 2018). Thus, for a given concentration of particles, those with more extreme aspect ratios and/or greater dielectric constants will lead to larger phase shifts (and thus larger $K_{\mathrm{DP}}$ ).

It is consistent with scattering theory that anomalously large $K_{\mathrm{DP}}$ and differential attenuation are frequently observed together: both are related to the complex forwardscattering coefficients of particles in the sampling volume. In the convention of Bringi and Chandrasekar (2001) and Ryzhkov (2001), $K_{\mathrm{DP}}$ is proportional to the difference in the real parts of the forward-scattering coefficients at horizontal and vertical polarizations, whereas $A_{\mathrm{DP}}$ is proportional to the difference in the imaginary parts. Both are also directly proportional to the number concentration of nonspherical particles in the sampling volume. For hydrometeors, the real and imaginary parts of the forward-scattering amplitudes often increase together for increasing particle size. Thus, $K_{\mathrm{DP}}$ and $A_{\mathrm{DP}}$ tend to increase together with increasing size of nonspherical particles. A greater imaginary part of the forward-scattering amplitude indicates a larger phase shift upon scattering, which increases the phase lag of the forward-scattered wave above $90^{\circ}$. It is instructive to consider the extreme cases: for zero imaginary part of the forward-scattering amplitude (i.e., the scattering amplitude is entirely real), the forward-scattered wave from a collection of particles is $90^{\circ}$ phase lagged relative to the incident wave; for scattering amplitudes that are entirely imaginary, the forward-scattered wave is $180^{\circ}$ phase lagged relative to the incident wave. In this latter case, the forward-scattered wave destructively interferes with the incident wave, reducing its intensity. Thus, the imaginary part of the forward-scattering amplitude can be thought of as the part that destructively interferes with the incident wave. This is a physical interpretation of the optical theorem (Bohren and Huffman 1983).

\section{b. T-matrix scattering calculations}

From the analysis presented in section 3 , the most notable polarimetric radar signatures associated with SPLASH cases involve anomalously large $K_{\mathrm{DP}}$ and differential attenuation. To test our hypothesis that these signatures arise from large concentrations of small melting hail, we perform T-matrix scattering calculations for particles representing melting hailstones. 

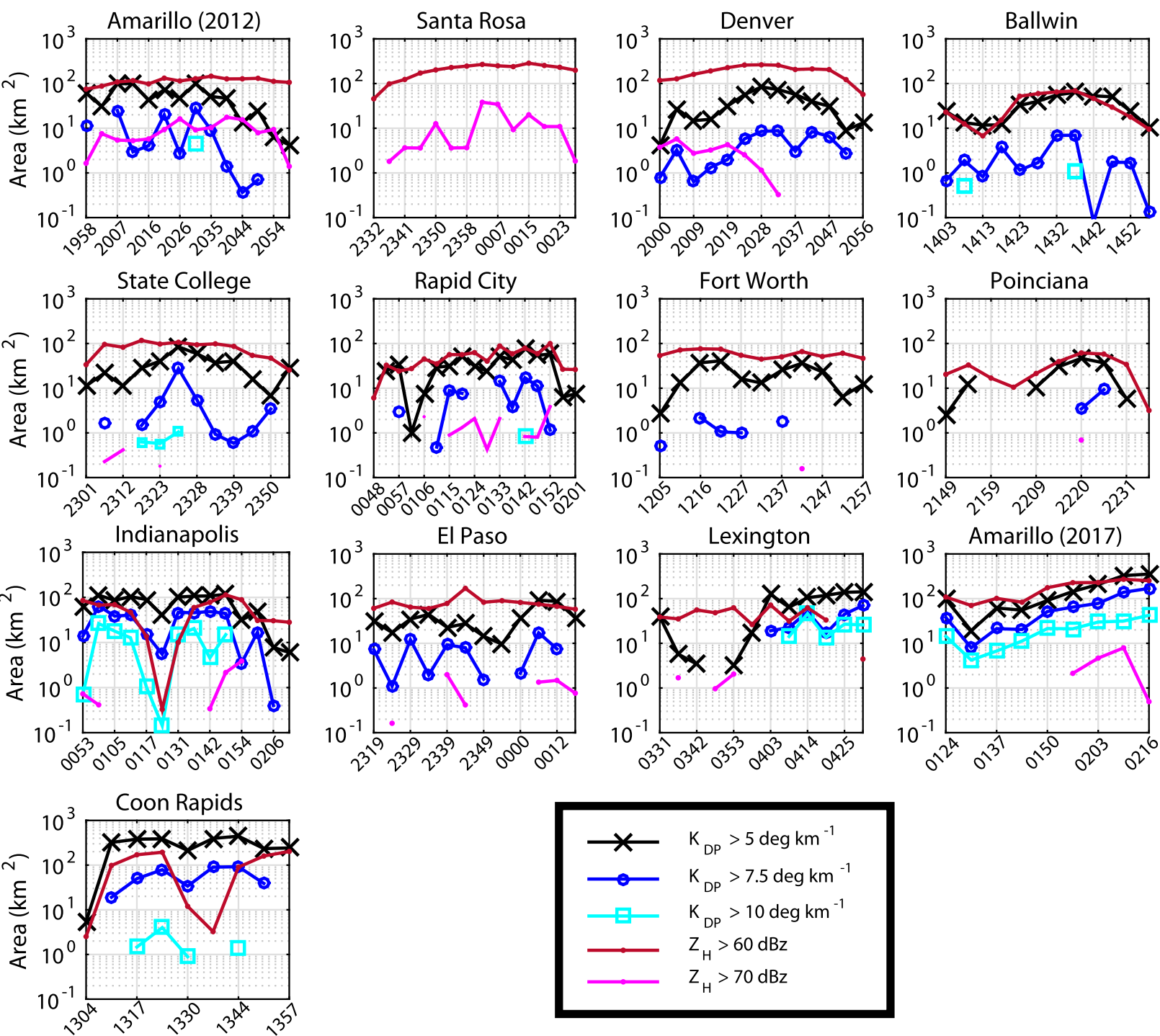

FIG. 11. Time series (as a function of volume scan; times listed are UTC) of the areas of enhanced $Z_{H}$ and $K_{\mathrm{DP}}$ during the analysis period for each of the 13 SPLASH cases. Black $\times$ markers and lines indicate $K_{\mathrm{DP}}>5^{\circ} \mathrm{km}^{-1}$, blue circles and lines indicate $K_{\mathrm{DP}}>7.5^{\circ} \mathrm{km}{ }^{-1}$, and cyan squares and lines indicate $K_{\mathrm{DP}}>10^{\circ} \mathrm{km}^{-1}$. Blood red lines with dot markers indicate $Z_{H}>60 \mathrm{~dB} Z$, whereas magenta lines and dots indicate $Z_{H}>70 \mathrm{~dB} Z$. Note that ordinate axes are in logarithmic scale.

The hailstones are modeled following numerous previous works, including Ryzhkov et al. (2013a) and Kumjian et al. (2018).

One way to put the extreme $K_{\mathrm{DP}}$ values in context is to consider the concentration of monodispersed melting hailstones and the condensed water content (both liquid and ice) required to produce $K_{\mathrm{DP}}$ values in excess of $10^{\circ} \mathrm{km}^{-1}$ (Fig. 13). For example, approximately ten $1-\mathrm{cm}$ melting hailstones per cubic meter are required for $K_{\mathrm{DP}}$ values to reach $10^{\circ} \mathrm{km}^{-1}$, which corresponds to about $2.5 \mathrm{~g} \mathrm{~m}^{-3}$ condensed water content. In general, we see from Fig. 13 that fewer oblate hailstones per cubic meter are required to produce extreme $K_{\mathrm{DP}}$ than more isometric hail. For all but the smallest melting hailstones, less than about $5 \mathrm{~g} \mathrm{~m}^{-3}$ of condensed water content produces the extreme $K_{\text {DP }}$ values.

If we consider that only melting hail of a given size contributes to $10^{\circ} \mathrm{km}^{-1} K_{\mathrm{DP}}$, we can also see what the corresponding $Z_{H}$ would be for the monodispersed distribution. Figure 14 shows that, if melting hailstones $>12-13 \mathrm{~mm}$ in diameter were the cause of the large $K_{\mathrm{DP}}$ values, then the corresponding $Z_{H}$ values would be unrealistically high $(>80 \mathrm{~dB} Z$; higher than observed in any of the SPLASH cases). This suggests two possibilities. First, the extreme $K_{\mathrm{DP}}$ comes from smaller $(<12-13 \mathrm{~mm})$ 


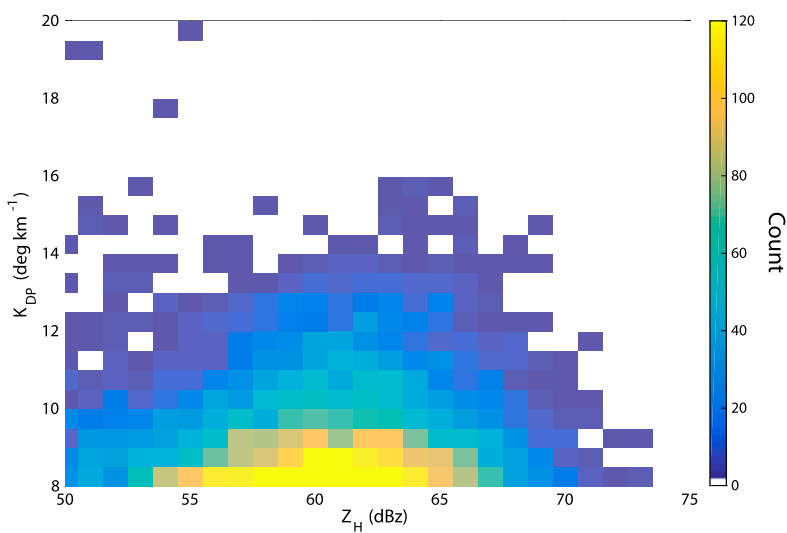

FIG. 12. Joint histogram showing the counts of pixels of enhanced $Z_{H}$ and $K_{\mathrm{DP}}$ for all 13 cases. Data were binned by $1 \mathrm{~dB}$ in $Z_{H}$ and $0.5^{\circ} \mathrm{km}^{-1}$ in $K_{\mathrm{DP}}$.

melting hailstones. Second, heavy $\operatorname{rain}^{2}\left(>100 \mathrm{~mm} \mathrm{~h}^{-1}\right.$ rainfall rates) from totally melted hailstones can contribute an additional $3^{\circ}-6^{\circ} \mathrm{km}^{-1}$ to $K_{\mathrm{DP}}$. This would shift the curves in Fig. 14 down by no more than about $3 \mathrm{~dB}$. In either case, it is likely that heavy rain and small melting hail dominate the contributions to $K_{\mathrm{DP}}$, whereas larger hailstones by themselves cannot explain the bulk of the $K_{\mathrm{DP}}$ (although they could easily dominate the high$Z_{H}$ returns). Those storms with $K_{\mathrm{DP}} \geq 10^{\circ} \mathrm{km}^{-1}$ but $Z_{H}<$ $70 \mathrm{~dB} Z$ may be characterized by large concentrations of hailstones $\leq 12 \mathrm{~mm}$ in maximum dimension. Those with $Z_{H}>70 \mathrm{~dB} Z$ likely suggest that some larger hail is present, in addition to the large concentrations of smaller melting hail.

Of most importance for explaining the observed radar signatures is the contribution of each particle size (0.1-40 $\mathrm{mm}$ in $0.1-\mathrm{mm}$ increments) to the total $Z_{H}$, $K_{\mathrm{DP}}$, two-way specific attenuation at horizontal polarization $A_{H}$, and two-way $A_{\mathrm{DP}}$. To quantify these contributions, we assume an exponential particle size distribution (PSD) with slope parameter $\Lambda$. The values are normalized such that the maximum contribution is equal to unity to remove the concentration dependence. We used a range of $\Lambda$ values from Ulbrich and Atlas (1982), who investigated the relationship between exponential size distribution parameters and maximum observed hail size $D_{\text {max }}$. They found $\Lambda \times D_{\max }=7.9$ was the average value for distributions from numerous observations; further, $90 \%$ of their cases had $\Lambda \times D_{\max }>5.0$. Using this relationship as a guide for a realistic range of $\Lambda$ values, our calculations show little sensitivity in the qualitative results of

\footnotetext{
${ }^{2}$ From our experience and our large disdrometer dataset (Morrison et al. 2019), $\sim 5^{\circ}-6^{\circ} \mathrm{km}^{-1}$ is about the highest one can expect for pure rain at $\mathrm{S}$ band.
}

which particle sizes contribute most to the total radar variables. For most gamma and exponential size distributions, the peak contribution to $K_{\mathrm{DP}}$ comes from $\sim 1$-cm-diameter ice cores, or roughly $12-\mathrm{mm}$ particle diameters. Therefore, calculations for a single PSD are provided in Fig. 15 for illustrative purposes.

From Fig. 15 we see that, although the particles dominating the contributions to $Z_{H}$ tend to be between 10 and $20 \mathrm{~mm}$ in size (Fig. 15a), the contributions to total $K_{\mathrm{DP}}$ and $A_{\mathrm{DP}}$ are dominated by particles smaller than about $12 \mathrm{~mm}$, which contain larger liquid water fractions and have axis ratios farther from unity than their larger counterparts in the Ryzhkov et al. (2013a) and Kumjian et al. (2018) parameterizations. There is a secondary peak for sizes between 14 and $16 \mathrm{~mm}$. For wider PSDs, the contributions to $Z_{H}$ and $A_{H}$ from larger stones increase (see, e.g., Ryzhkov et al. 2013a,b). Of course, assuming other shapes for the PSD (including a gamma PSD) would affect the details of these results. Regardless of the selected PSD shape, however, the main conclusion still holds: the larger stones tend to dominate $Z_{H}$ (and thus $Z_{\mathrm{DR}}$ ) and $A_{H}$, whereas smaller melting stones dominate contributions to $K_{\mathrm{DP}}$ and $A_{\mathrm{DP}}$, in agreement with Ryzhkov et al. (2013a,b). Thus, in some cases with a broad distribution of sizes, the presence of larger hail in the radar sampling volume may lead to the classic high- $Z_{H}$ and low- $Z_{\mathrm{DR}}$ signature, although anomalously high $K_{\mathrm{DP}}$ and $A_{\mathrm{DP}}$ could reveal the presence of large concentrations of smaller melting stones and large raindrops whose contributions to $Z_{H}$ and $Z_{\mathrm{DR}}$ are dwarfed by the larger stones. In this way, the dualpolarization radar variables provide information about different parts of the hail size distribution.

Figure 16 shows the polarimetric radar variables over a range of different exponential PSDs, defined by the intercept parameter $N_{0}$ and slope parameter $\Lambda$. Each panel is overlaid with $Z_{H}$ contours from 50 to $80 \mathrm{~dB} Z$ in $10-\mathrm{dB}$ increments. Each polarimetric variable exhibits different sensitivities to the two PSD parameters. For example, $Z_{\mathrm{DR}}$ is insensitive to $N_{0}$ and is only a function of $\Lambda$, whereas the other radar variables are sensitive to both $N_{0}$ and $\Lambda$ in varying degrees, as indicated by their different functional dependences on both $N_{0}$ and $\Lambda$. For realistic $Z_{H}$ values (i.e., $<80 \mathrm{~dB} Z$ ), the maximum calculated $K_{\mathrm{DP}}$ values in Fig. 16 fall short of observations. However, our calculations assume only the presence of melting hailstones and not the raindrops resulting from complete melting or shedding. Real storms generally exhibit heavy rainfall originating from total melting of the smallest hailstones and shedding (e.g., Rasmussen and Heymsfield 1987; Kumjian et al. 2015). Such heavy convective rain could easily add an additional $3^{\circ}-6^{\circ} \mathrm{km}^{-1}$ to $K_{\mathrm{DP}}$, as mentioned above. Importantly, however, the addition of heavy rain to the sampling volume 

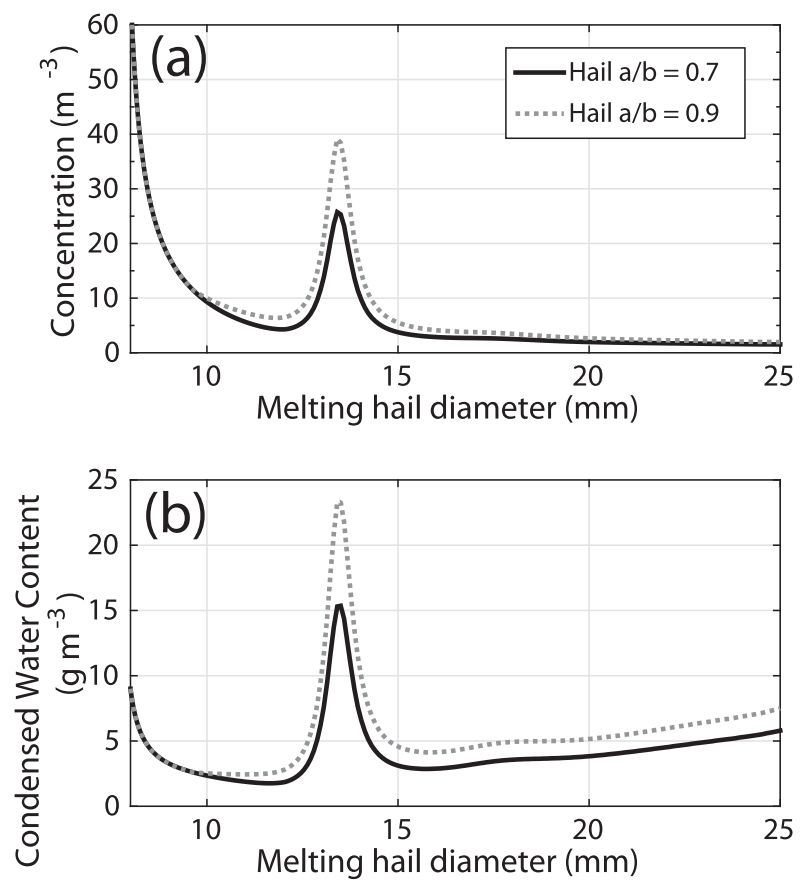

FIG. 13. (a) Concentration of melting hail as a function of size needed for $K_{\mathrm{DP}}>10^{\circ} \mathrm{km}^{-1}$, assuming a monodispersed size distribution. (b) As in (a), but for the total mass content of condensed water (liquid and ice). The black lines show dry hailstone aspect ratio equal to 0.7 , whereas the dotted gray lines show dry hailstone aspect ratio equal to 0.9 .

containing large concentrations of small hail negligibly affects $Z_{H}$ and $Z_{\mathrm{DR}}$. This is because when $Z_{H}>65 \mathrm{~dB} Z$ or so (from the hail), rain contributes very little; the heaviest rain is expected to be no more than $\sim 55 \mathrm{~dB} Z$, an order of magnitude or less than the contributions from hail. In contrast, $K_{\mathrm{DP}}$ adds linearly. Consider an example gamma PSD with $N_{0}=5 \mathrm{~m}^{-3} \mathrm{~mm}^{-1}, \Lambda=0.6 \mathrm{~mm}^{-1}$, and $\mu=2$. This results in $Z_{H}=75.5 \mathrm{dBZ}, Z_{\mathrm{DR}}=2.8 \mathrm{~dB}$, $K_{\mathrm{DP}}=7.1^{\circ} \mathrm{km}^{-1}$, and $A_{\mathrm{DP}}=0.32 \mathrm{~dB} \mathrm{~km}^{-1}$. With an additional $3^{\circ}-6^{\circ} \mathrm{km}^{-1}$ and $55 \mathrm{~dB} Z$ from heavy rain, the total $K_{\mathrm{DP}}$ becomes $10^{\circ}-13^{\circ} \mathrm{km}^{-1}$, whereas the total $Z_{H}$ increases by only $0.04 \mathrm{~dB}$. Thus, the scattering calculations for melting hailstones alone are consistent with, and thus plausibly explain, the observations when the addition of heavy rain is considered.

\section{Environmental analysis}

Next, we investigate the environments for the SPLASH cases. As described above, we take RAP-model output surrounding the grid point containing the hail report and construct distributions of relevant RAP-predicted severe storm environmental parameters, including surface-based CAPE, 0-6-km bulk wind difference, precipitable water, and $0-1-$ and $0-3-\mathrm{km}$ storm-relative helicity. In addition,

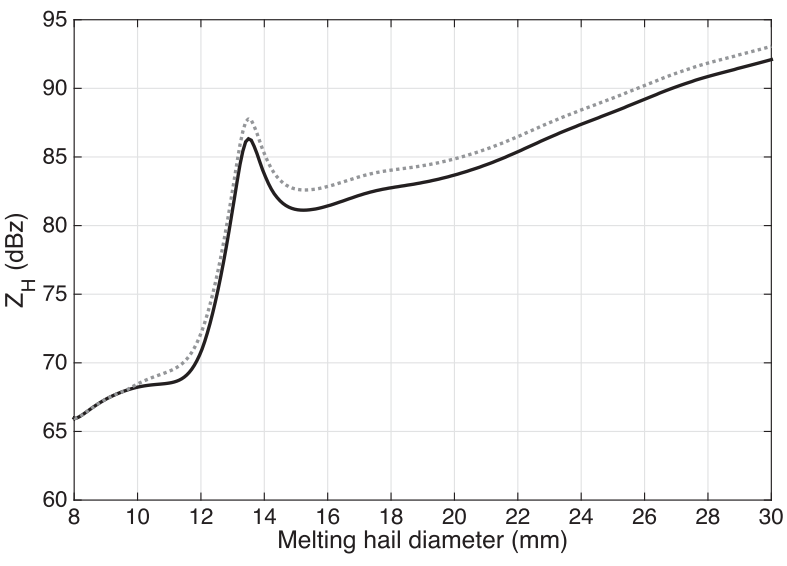

FIG. 14. The $Z_{H}$ obtained from a monodispersed size distribution of melting hailstones (size is on the abscissa) to achieve $K_{\mathrm{DP}}$ of $10^{\circ} \mathrm{km}^{-1}$. The black solid line indicates calculations for dry hailstone aspect ratio of 0.7 , and dotted gray lines indicate aspect ratio is 0.9 .

we compare these model-based distributions to climatological values from the nearest operational soundings for that day from the SPC's sounding climatology (http://www. spc.noaa.gov/exper/soundingclimo/\#), with zero-CAPE days removed. The median (50th percentile) and 90th percentile values for the given day of the report are provided for context. This allows us to assess whether or not the environment supporting the SPLASH case was anomalous for that location and time of year. Note that this climatology does not contain information about whether a storm actually formed, so the distributions may include days for which there were no deep convective storms.

Figure 17 shows the distributions of surface-based CAPE for each case. Seven of the cases have median values larger than the climatological 90th percentile value for that day. Near-zero CAPE for the Fort Worth and Coon Rapids cases suggests that these cases had environments unstable for parcels lifted from somewhere other than the surface [i.e., the most unstable CAPE (MUCAPE) was nonzero]. Indeed, the 1200 UTC observed sounding from the Fort Worth case had $1514 \mathrm{~J} \mathrm{~kg}^{-1}$ of MUCAPE for a parcel lifted from $861 \mathrm{hPa}$, and the 1200 UTC observed sounding from the Coon Rapids case exhibited $1890 \mathrm{~J} \mathrm{~kg}^{-1}$ of MUCAPE for a parcel lifted from $825 \mathrm{hPa}$. These two cases of zero surface-based CAPE were both considered in the RAP-model verification discussed above (see Figs. S15, S18, S20, and S23). Despite these climatologically large values for the rest of the cases, however, the median CAPE values are less than $2500 \mathrm{~J} \mathrm{~kg}^{-1}$, which is modest when compared with values on significant severe weather days. Indeed, all but two cases exhibit median values below $1500 \mathrm{~J} \mathrm{~kg}^{-1}$. CAPE can be considered to be a rough proxy for maximum updraft speed (e.g., Markowski and Richardson 2010), 

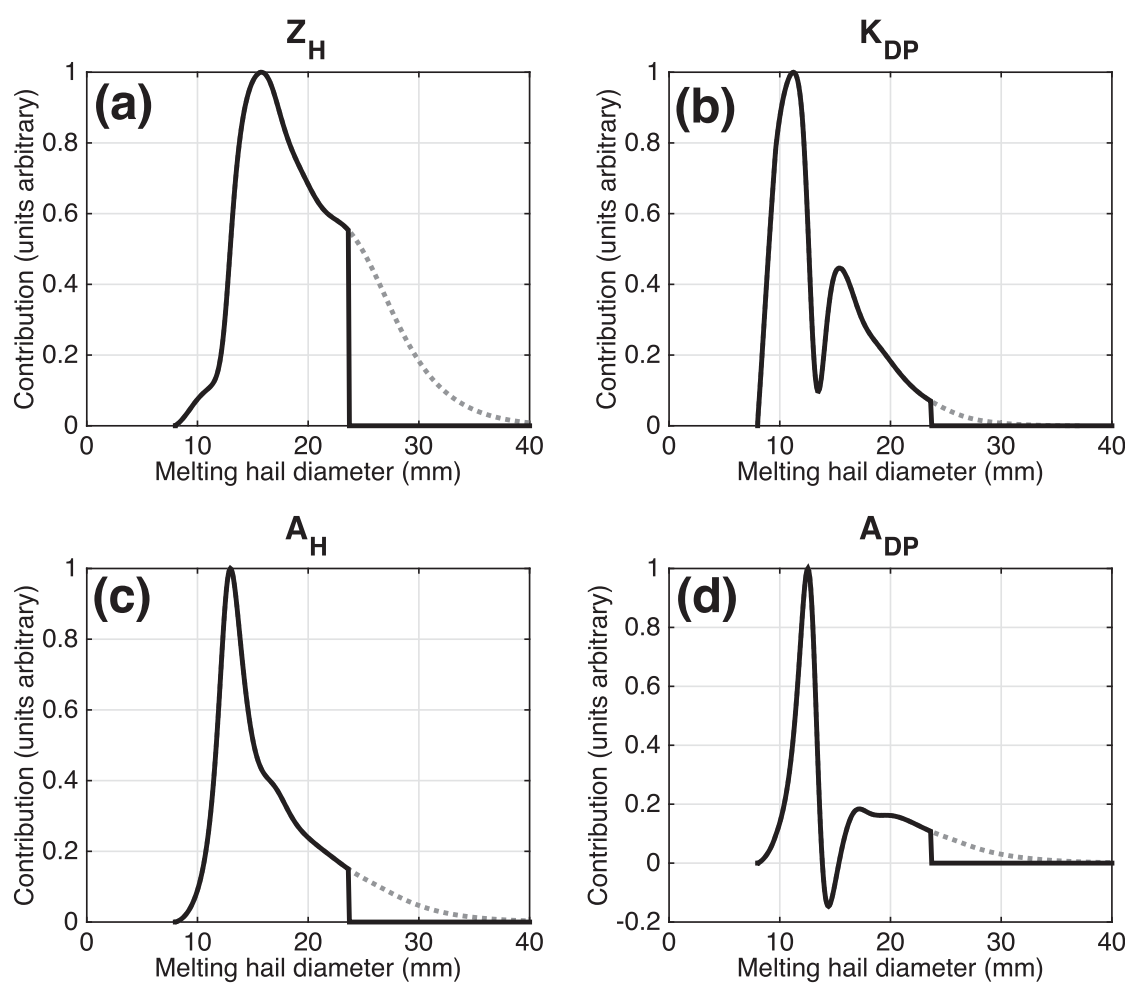

FIG. 15. T-matrix calculations showing normalized contributions of different hailstone sizes to the total polarimetric radar variables (a) $Z_{H}$, (b) $K_{\mathrm{DP}}$, (c) $A_{H}$, and (d) $A_{\mathrm{DP}}$, assuming an exponential particle size distribution. Calculations are valid at $S$ band. The dotted gray line shows the contributions of particles larger than $D_{\max }$ as defined by Ulbrich and Atlas (1982).

which is generally thought to provide an upper limit on the maximum hail size for a given storm. Thus, the relatively modest CAPE values for the SPLASH cases suggest that very large hail sizes are unattainable in those environments.

The distributions of 0-6-km bulk shear (Fig. 18) do not reveal a clear signal. Ten of the cases have median values that fall within the expected climatological 50th-90thpercentile values, although the Coon Rapids case (a QLCS) stands out as having the largest deep-layer shear. The overall unremarkable distributions suggest environmental deep-layer shear is not extreme in these events. Similarly, no clear signal is observed for $0-1$ - or 0-3-km storm-relative helicity (not shown). In contrast, the median precipitable water (PWAT) values (Fig. 19) are above the climatological 90th-percentile value for each day in all but three cases. For those three exceptions, the PWAT values are still close to the 90th-percentile value. This result suggests that an abundance of moisture is available throughout the troposphere for the storms. Moisture is a key ingredient in hail formation, so its abundance seemingly would be conducive to hail production. Note that Kalina et al. (2016) similarly found anomalously large PWAT for their four SPLASH cases in Colorado.
Several studies have highlighted the importance of storm airflow patterns in hail production (Nelson 1983; Tessendorf et al. 2005; Dennis and Kumjian 2017). Although low-level storm-relative helicity and deep-layer shear did not reveal any systematic patterns for these cases, these bulk quantities do not capture possible nuances of the hodograph and wind profiles. To explore these results in more detail, we take the vertical profiles of storm-relative wind speed (i.e., the RAP-model-output storm motion vector is subtracted from the winds at each level) averaged over the grid boxes surrounding the hail report. We interpolate the profiles onto a common temperature grid; we argue that plotting the storm-relative winds against temperature is more physically meaningful for hail production than altitude AGL. The average stormrelative wind speed at each temperature level is plotted in Fig. 20, along with the \pm 1 standard deviation about the average. These storm-relative wind profiles are similar, especially below the environmental $0^{\circ} \mathrm{C}$ level, as denoted by the narrow range in the mean \pm 1 standard deviation. For each case, the lowest levels are characterized by relatively weak $\left(<10 \mathrm{~m} \mathrm{~s}^{-1}\right.$ on average) storm-relative wind speeds that increase slowly with height. At about the environmental $0^{\circ} \mathrm{C}$ level and above, the storm-relative wind 

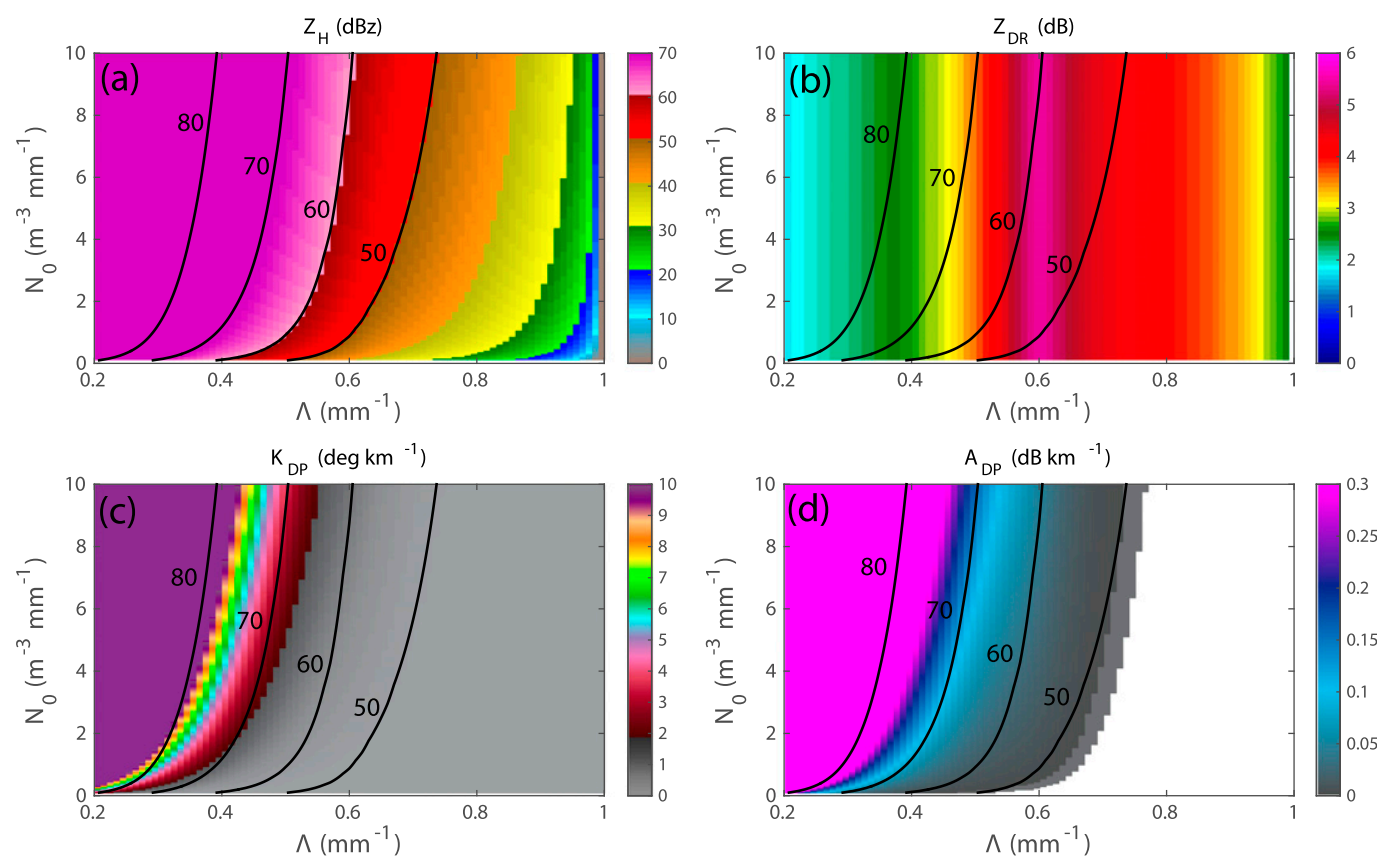

FIG. 16. Total (a) $Z_{H}$ (dBZ, shaded according to the scale), (b) $Z_{\mathrm{DR}}$ (dB, shaded according to the scale), (c) $K_{\mathrm{DP}}$ $\left({ }^{\circ} \mathrm{km}^{-1}\right.$, shaded according to the scale), and (d) $A_{\mathrm{DP}}\left(\mathrm{dB} \mathrm{km}^{-1}\right.$, shaded according to the scale) as a function of exponential particle size distribution parameters $\Lambda$ and $N_{0}$. Overlaid in each panel are $Z_{H}$ contours of 50,60,70, and $80 \mathrm{dBZ}$ (annotated black lines)

speeds increase with height for most cases, with increasing spread from case to case compared to at lower levels.

For comparison with the opposite extreme of hail size, we also plot the RAP-derived vertical profiles of storm-relative wind speeds from three record large hail cases: the Vivian, South Dakota, case that produced a $>20.3-\mathrm{cm}$ ( $>8$ in.) stone on 23 July 2010; the 15 September 2010 storm in Wichita, Kansas, that produced the Kansas state record hailstone $[19.7 \mathrm{~cm}$ (7.75 in.)], and the storm that produced the Oklahoma state record hailstone $[15.2 \mathrm{~cm}$ (6in.)] in Gotebo, Oklahoma. All three of these cases reveal greater stormrelative wind speeds in the lowest few kilometers, followed by a rapid decline to values that are less than 1 standard deviation below the mean of the SPLASH cases, and then a steady increase above that. Except for the lowest few kilometers, these three giant hail-producing storms had environments with vertical profiles of stormrelative winds that are similar to those of the SPLASH cases. Of course, these three cases also had larger CAPE values than did the SPLASH cases (not shown).

Next, we consider the storm-relative hodographs from each case. Because of the variability in large-scale flow directions among the different cases, we first rotate the hodograph coordinate system by an angle $\psi$ such that the new $x$ axis $\left(x^{\prime}\right)$ is aligned with the $0-6-\mathrm{km}$ shear vector, following Parker (2014). The winds at each height are decomposed into their new $u^{\prime}$ and $v^{\prime}$ components using $\psi$. Last, these rotated hodographs are composited. For each height level, the mean and standard deviation $u^{\prime}$ and $v^{\prime}$ components are computed. The resulting composite hodograph and variability (horizontal and vertical bars represent \pm 1 standard deviation) are shown in Fig. 21.

The lowest several kilometers have surprisingly low variability $\left(<2 \mathrm{~m} \mathrm{~s}^{-1}\right.$ in $u^{\prime}$ and $v^{\prime}$ below $\left.2 \mathrm{~km} \mathrm{AGL}\right)$. The classic clockwise-turning hodograph is consistent with 10 of these storms being right-moving supercells (Table 1 ). Overall, however, there is little shear in the $v^{\prime}$ component ( $<5 \mathrm{~m} \mathrm{~s}^{-1}$ over any layer). Recall that, with the rotation employed prior to compositing, $v^{\prime}$ represents the storm-relative winds in the direction normal to the 0-6-km shear vector. Dennis and Kumjian (2017) found that the updraft, and thus favorable embryo injection regions, are elongated in the direction of the deep-layer shear (here, the $u^{\prime}$ direction). The composite hodograph does not exhibit particularly strong $0-6-\mathrm{km} u^{\prime}$ shear (less than about $20 \mathrm{~m} \mathrm{~s}^{-1}$ ), indicating that the updraft elongation may not be significant in these cases (on average). In addition, the weakness or lack of $v^{\prime}$ flow below $6 \mathrm{~km}$ AGL means that storm-relative flow is largely parallel to the deep-layer shear at most levels. This weakness of the $v^{\prime}$ component of storm-relative flow appears to be more substantial than can be inferred from the composite hodographs shown in Johnson and Sugden (2014) 


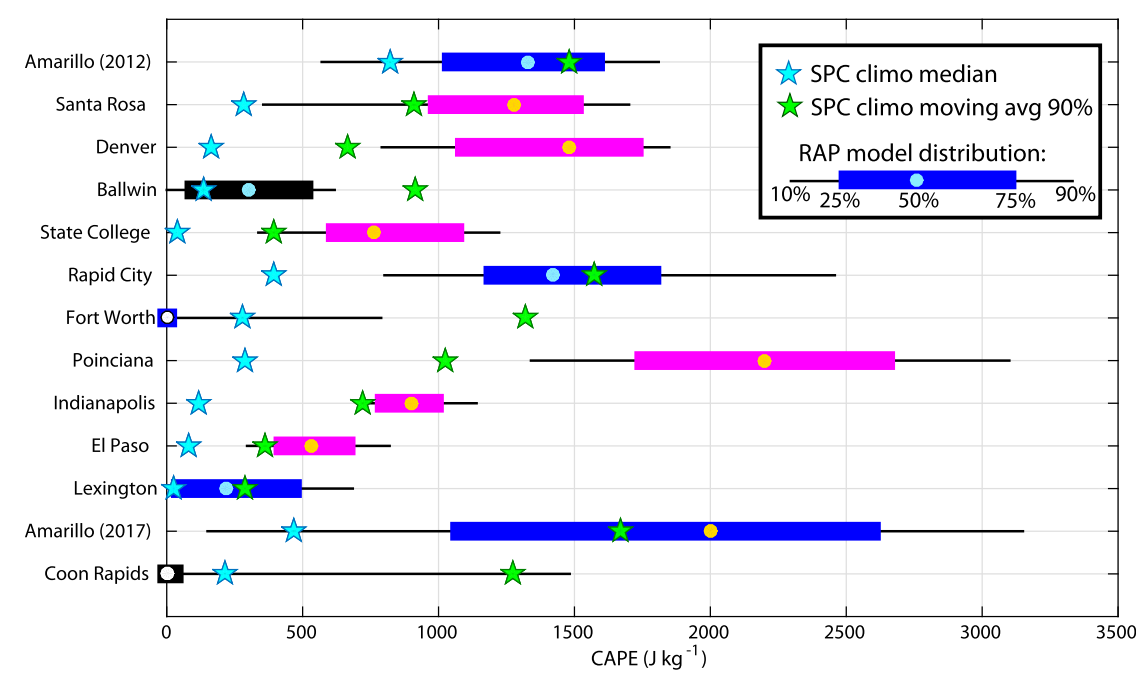

FIG. 17. Box-and-whisker plots of RAP-model-analyzed surface-based CAPE $\left(\mathrm{J} \mathrm{kg}^{-1}\right)$ for each case. The box and whiskers correspond to different percentiles of the distribution, as indicated in the legend. The cyan and chartreuse star markers indicate SPC daily sounding climatology median and moving-average 90th-percentile values. The interquartile range (IQR) is colored according to the following convention. Black indicates that the IQR does not exceed the climatological median. Blue indicates that the IQR exceeds the climatological median. Magenta indicates the IQR exceeds the climatological 90th-percentile values. The median marker is colored white, pale blue, and goldenrod if it is below the climatological median, between the climatological median and 90th percentile, or above the climatological 90th percentile, respectively.

for storms that produced larger hail sizes. We speculate that this may inhibit favorable embryo trajectories for significant growth. The generally weaker updrafts owing to only modest CAPE in the SPLASH cases probably also prevent the formation of very large hail (cf. Table 2).

\section{Discussion}

In contrast to this study, Kalina et al. (2016) did not find anomalously large $K_{\mathrm{DP}}$ in the four storms considered in that study. Kalina et al. (2016) also used the
Hubbert and Bringi (1995) filter, but applied it to the data for four iterations. Here, we only applied the filter once; our tests show that iterating four times leads to overly excessive smoothing. For the Indianapolis case, we tested the different number of iterations on 10 radials (not shown). The difference in the resulting maximum $K_{\text {DP }}$ values between a single iteration and four iterations varied between $1^{\circ}$ and $6^{\circ} \mathrm{km}^{-1}$, with an average underestimate of $3.2^{\circ} \mathrm{km}^{-1}$ for the excessive smoothing. This may have contributed to Kalina et al. (2016) not finding any large $K_{\mathrm{DP}}$ values in their analysis of four

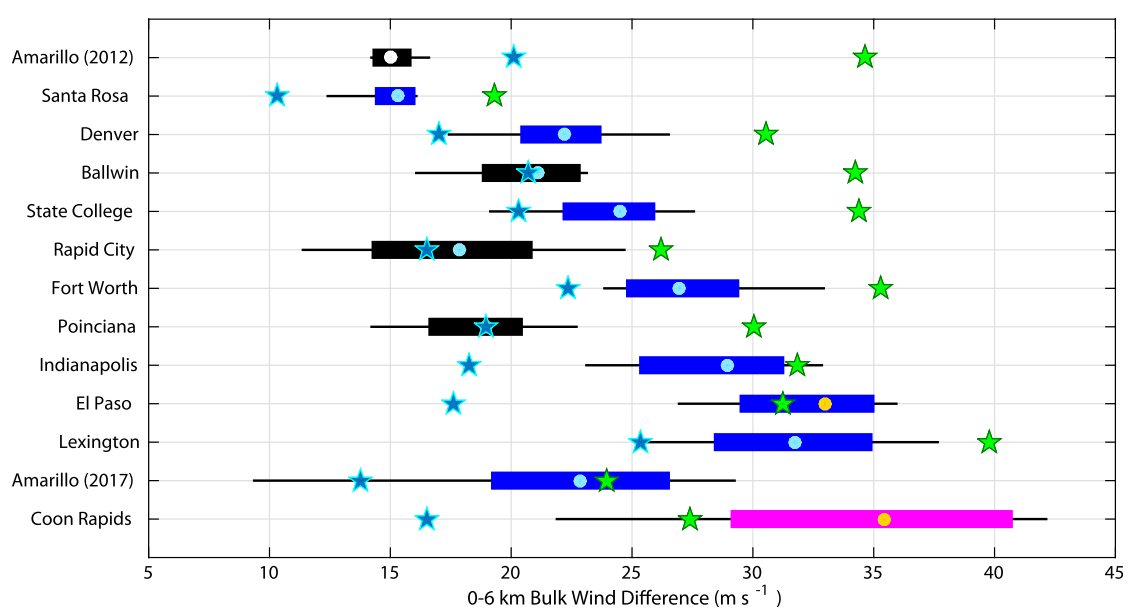

FIG. 18. As in Fig. 17, but for 0-6-km bulk wind difference $\left(\mathrm{m} \mathrm{s}^{-1}\right)$. 


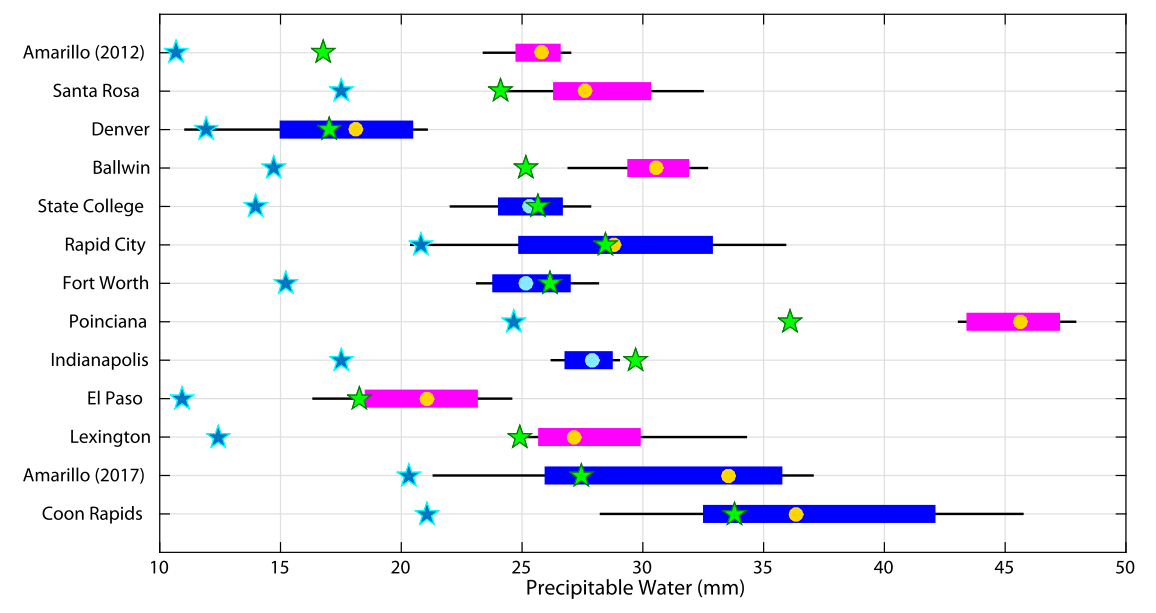

FIG. 19. As in Fig. 17, but for PWAT values (mm).

Colorado storms. In addition, those authors regridded the radar data onto a Cartesian grid, so interpolation could also have played a role in reducing values. In the 21 May 2014 case that was examined in both studies, our maximum $K_{\mathrm{DP}}$ values were near $8.6^{\circ} \mathrm{km}^{-1}$ (not shown), consistent with those in the level-III data (Fig. 5c) and inconsistent with those of $<3^{\circ} \mathrm{km}^{-1}$ that were found in Kalina et al. (2016, their Fig. 12d). Kalina et al. (2016) also noted substantially negative $Z_{\mathrm{DR}}$ values in their cases, but they attributed this to large hail and/or threebody scattering. The majority of the cases analyzed herein show that differential attenuation is the cause of the negative $Z_{\mathrm{DR}}$ values downrange of the high- $Z_{H}$ cores. The close correlation found in the scattering calculations between large $K_{\mathrm{DP}}$ and large $A_{\mathrm{DP}}$ further supports this conclusion.

If we consider typical U.S. Great Plains supercells, many contain severe hail (Blair et al. 2017) but do not often exhibit the anomalously large $K_{\mathrm{DP}}$, in our experience. This implies a broader hail size distribution than the cases of accumulating small hail shown herein. It is tempting to consider that perhaps the mass from what would otherwise be larger hail sizes in typical storms is instead contained in a narrow range of smaller sizes in these SPLASH cases, as if the pathways for growth of larger stones are inhibited. To better understand why these storms produce large amounts of small hail and/or have large hail pathways that are inhibited, it may be instructive to consider hail-growth processes that result in large hail. The main ingredients for large hail include sufficient amounts of supercooled liquid water, availability of millimeter-sized particles to serve as hailstone embryos, a sufficiently strong updraft, and trajectories that are conducive to long residence times within the updraft (e.g., Nelson 1983; Heymsfield 1983; Foote 1984; Dennis and Kumjian 2017, among many others). The plethora of hailstones observed in the cases studied herein suggests that embryos and perhaps supercooled liquid water are not in short supply (the latter would seem to be supported indirectly by large precipitable water values found in the storm environments). Thus, we speculate that a lack of sufficient residence time and/ or a lack of a broad region of moderate updraft velocities (Nelson 1983) are culprits. The modest vertical wind shear and weakness of storm-relative flow perpendicular to the deep-layer shear vector could be factors that inhibit updraft width and/or trajectories leading to large residence times. Detailed growth trajectory modeling

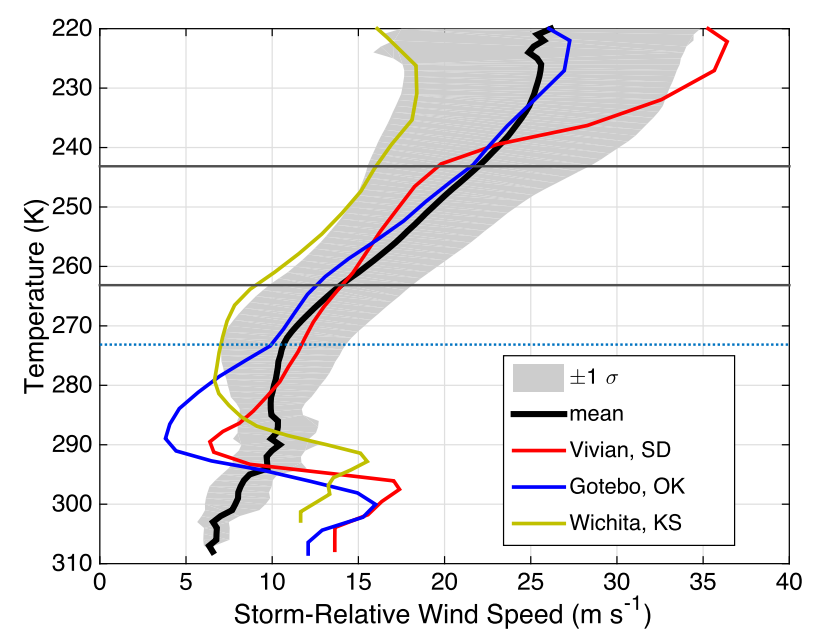

FIG. 20. Profiles of the average storm-relative wind speed $\left(\mathrm{m} \mathrm{s}^{-1}\right.$; black curve) for all cases as a function of temperature (K) from the RAP-model analyses, with gray shading representing \pm 1 standard deviation about the mean. The horizontal blue dashed line indicates $0^{\circ} \mathrm{C}$, whereas the horizontal gray lines indicate the hailgrowth region (from $-10^{\circ}$ to $-30^{\circ} \mathrm{C}$ ). Overlaid are the profiles from record hail days as colored lines: Vivian in red, Gotebo in blue, and Wichita in gold. 


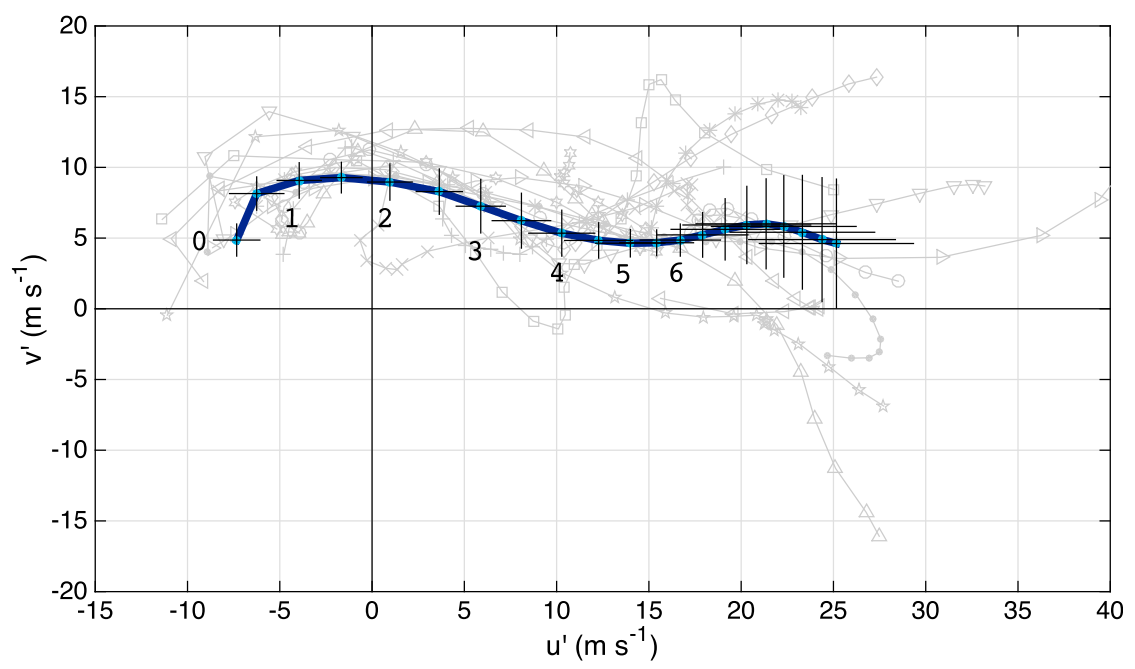

FIG. 21. Rotated 0-10-km storm-relative hodographs for each case (thin gray lines) overplotted by the composite of all cases (dark blue line). Error bars show \pm 1 standard deviation for $u^{\prime}$ and $v^{\prime}$ and are plotted every $0.5 \mathrm{~km}$ in altitude. Altitudes AGL are labeled every $1 \mathrm{~km}$ from 0 to $6 \mathrm{~km}$.

(e.g., Dennis and Kumjian 2017) could be used in future work to further elucidate these factors.

\section{Summary and conclusions}

We investigated 13 cases of storms producing large amounts of small hail (SPLASH) from geographically diverse regions (see Table 1). These storms formed in diverse environments and had a range of storm motions, indicating that a variety of different environmental conditions may lead to SPLASH events. However, there are several environmental features in common among the storms, at least according to RAP-model output: large precipitable water values ( $>90$ th percentile of the daily climatological values), CAPE below $2500 \mathrm{~J} \mathrm{~kg}^{-1}$, weak low-level storm-relative wind speeds $\left(<10 \mathrm{~m} \mathrm{~s}^{-1}\right.$ in the lowest few kilometers), and a weak component of flow perpendicular to the $0-6-\mathrm{km}$ shear vector $\left(<10 \mathrm{~m} \mathrm{~s}^{-1}\right.$, but generally $5 \mathrm{~m} \mathrm{~s}^{-1}$ or less). Overall, the $0-6-\mathrm{km}$ bulk wind difference was typically below $30 \mathrm{~m} \mathrm{~s}^{-1}$. Anomalously large precipitable water values were also reported by Kalina et al. (2016); however, the slow storm motions also reported in that study were not found to be typical in our cases. As such, although slow storm motions undoubtedly could contribute to large hail accumulations, it does not appear to be a necessary condition. Future work should focus on additional SPLASH cases for which reasonably representative proximity soundings exist to further evaluate these RAP-model-based inferences.

Further, the storms exhibited distinctive signatures in their dual-polarization radar presentations. These include compact low-level $Z_{H}$ structures, with maximum
$Z_{H}$ values of $>65-70 \mathrm{~dB} Z$, anomalously large $K_{\mathrm{DP}}$ values (often greater than $10^{\circ} \mathrm{km}^{-1}$, which is off the National Weather Service operational color scale), and anomalously large differential attenuation manifested as swaths of negative $Z_{\mathrm{DR}}$ extending far downrange of the hail core. The $K_{\mathrm{DP}}$ and $Z_{\mathrm{DR}}$ signatures were the most striking and reliable for the storms studied herein. These signatures were not reported in Kalina et al. (2016), likely owing to overly aggressive smoothing of $\Phi_{\mathrm{DP}}$ and thus underestimation of $K_{\mathrm{DP}}$ in that study. Electromagnetic scattering calculations using the T-matrix method confirm that small melting hailstones are likely the most dominant contributors to the observed extreme $K_{\mathrm{DP}}$ and $A_{\mathrm{DP}}$. The likely addition of heavy rain would contribute even more to $K_{\mathrm{DP}}$ but only minimally to $Z_{H}$ and $Z_{\mathrm{DR}}$, given the very large $Z_{H}$ already contributed by the presence of hail.

The repeatability of anomalous radar signatures with these storms provides guidance for real-time detection of hazardous hail accumulations. It is recommended that operational $K_{\mathrm{DP}}$ estimation allow values in excess of $10.7^{\circ} \mathrm{km}^{-1}$ to better quantify the threat from large amounts of small hail; our calculations and scattering theory show that $K_{\mathrm{DP}}$ scales with the small melting hail mass. So, all else being equal, large $K_{\mathrm{DP}}$ implies larger quantities of small melting hail and potentially larger accumulations. Unfortunately, we are left with an incomplete understanding of why some environments, storm structures, or behaviors lead to so much small hail. Future work will involve continued analysis of additional cases as well as numerical modeling and trajectory calculations following the method of Dennis and Kumjian (2017) in an effort to better understand and 
ultimately anticipate the storm structures and behaviors and environmental factors that contribute to production of large accumulations of small hail.

Acknowledgments. The first author is grateful for funding provided by the National Science Foundation through Grant AGS-1661679 and from an award from the Insurance Institute for Business and Home Safety (IBHS); Dr. Charlie Knight and two anonymous reviewers provided thorough critiques of the manuscript that substantially improved its clarity and presentation. Thanks are given to Dr. Scott Ellis (NCAR) for providing the Matlab script for the finite impulse response filter. We thank those who provided images of accumulated hail: Beverly Aycock, Valerie Castro, Marisa Ferger, Tim Hagerty, Mallory Hatton, Ivory Hecker, Josh Johnson, Tiffany Karnes, Joseph Lee, Catherine Musser, Mike Roach, Lauren Schenk, Michelle Swan, Potter County Emergency Management, and the Santa Rosa Fire Department. This paper is dedicated to the memory of Ginette Kumjian.

\section{REFERENCES}

Allen, J. T., M. K. Tippett, Y. Kaheil, A. H. Sobel, C. Lepore, S. Nong, and A. Muehlbauer, 2017: An extreme value model for U.S. hail size. Mon. Wea. Rev., 145, 4501-4519, https://doi.org/ 10.1175/MWR-D-17-0119.1.

Aydin, K., T. A. Seliga, and V. Balaji, 1986: Remote sensing of hail with a dual linear polarized radar. J. Climate Appl. Meteor., 25, 1475-1484, https://doi.org/10.1175/1520-0450(1986)025<1475: RSOHWA $>2.0 . \mathrm{CO} ; 2$.

Benjamin, S. G., and Coauthors, 2016: A North American hourly assimilation and model forecast cycle: The Rapid Refresh. Mon. Wea. Rev., 144, 1669-1694, https://doi.org/10.1175/ MWR-D-15-0242.1.

Blair, S. F., D. R. Deroche, J. M. Boustead, J. W. Leighton, B. L. Barjenbruch, and W. P. Gargan, 2011: A radar-based assessment of the detectability of giant hail. Electron. J. Severe Storms Meteor., 6 (7), https://www.ejssm.org/ojs/index.php/ ejssm/article/viewFile/87/.

__ , and Coauthors, 2017: High-resolution hail observations: Implications for NWS warning operations. Wea. Forecasting, 32, 1101-1119, https://doi.org/10.1175/WAF-D16-0203.1.

Bohren, C. F., and D. R. Huffman, 1983: Absorption and Scattering of Light by Small Particles. 1st ed. Wiley-VCH, 547 pp.

Bringi, V. N., and T. A. Seliga, 1977a: Scattering from axisymmetric dielectrics or perfect conductors imbedded in an axisymmetric dielectric. IEEE Trans. Antennas Propag., 25, 575-580, https:// doi.org/10.1109/TAP.1977.1141642.

— Ann. Telecommun., 32, 392-397.

— , and V. Chandrasekar, 2001: Polarimetric Doppler Weather Radar. 1st ed. Cambridge University Press, 636 pp.

Brown, T. M., W. H. Pogorzelski, and I. M. Giammanco, 2015: Evaluating hail damage using property insurance claims data. Wea. Climate Soc., 7, 197-210, https://doi.org/10.1175/ WCAS-D-15-0011.1.
Chandrasekar, V., R. Keranen, S. Lim, and D. Moisseev, 2013: Recent advances in classification of observations from dual polarization weather radars. Atmos. Res., 119, 97-111, https:// doi.org/10.1016/j.atmosres.2011.08.014.

Changnon, S., D. Changnon, and S. D. Hilberg, 2009: Hailstorms across the nation: An atlas about hail and its damages. Illinois State Water Survey Contract Rep. 2009-12, 92 pp.

Cintineo, J. L., T. M. Smith, V. Lakshmanan, H. E. Brooks, and K. L. Ortega, 2012: An objective high-resolution hail climatology of the contiguous United States. Wea. Forecasting, 27, 1235-1248, https://doi.org/10.1175/WAF-D-11-00151.1.

Dennis, E. J., and M. R. Kumjian, 2017: The impact of vertical wind shear on hail growth in simulated supercells. J. Atmos. Sci., 74, 641-663, https://doi.org/10.1175/JAS-D-16-0066.1.

Edwards, R., and R. L. Thompson, 1998: Nationwide comparisons of hail size with WSR-88D vertically integrated liquid water and derived thermodynamic sounding data. Wea. Forecasting, 13, 277-285, https://doi.org/10.1175/1520-0434(1998)013<0277: $\mathrm{NCOHSW}>2.0 . \mathrm{CO} ; 2$.

Foote, G. B., 1984: A study of hail growth utilizing observed storm conditions. J. Climate Appl. Meteor., 23, 84-101, https://doi.org/ 10.1175/1520-0450(1984)023<0084:ASOHGU>2.0.CO;2.

Giammanco, I. M., T. M. Brown, R. G. Grant, D. L. Dewey, J. D. Hodel, and R. A. Stumpf, 2015: Evaluating the hardness characteristics of hail through compressive strength measurements. J. Atmos. Oceanic Technol., 32, 2100-2113, https:// doi.org/10.1175/JTECH-D-15-0081.1.

Giangrande, S. E., and A. V. Ryzhkov, 2008: Estimation of rainfall based on the results of polarimetric echo classification. J. Appl. Meteor. Climatol., 47, 2445-2462, https://doi.org/10.1175/ 2008JAMC1753.1.

_ R. McGraw, and L. Lei, 2013: An application of linear programming to polarimetric radar differential phase processing. J. Atmos. Oceanic Technol., 30, 1716-1729, https://doi.org/ 10.1175/JTECH-D-12-00147.1.

Grant, L. D., and S. C. van den Heever, 2014: Microphysical and dynamical characteristics of low-precipitation and classic supercells. J. Atmos. Sci., 71, 2604-2624, https://doi.org/10.1175/ JAS-D-13-0261.1.

Gunturi, P., and M. Tippett, 2017: Managing severe thunderstorm risk: Impact of ENSO on U.S. tornado and hail frequencies. Willis Re Tech. Rep., 5 pp., http://www.willisre.com/Media_Room/ Press_Releases_(Browse_All)/2017/WillisRe_Impact_of_ ENSO_on_US_Tornado_and_Hail_frequencies_Final.pdf.

Heymsfield, A. J., 1983: Case study of a hailstorm in Colorado. Part IV: Graupel and hail growth mechanisms deduced through particle trajectory calculations. J. Atmos. Sci., 40, 1482-1509, https:// doi.org/10.1175/1520-0469(1983)040<1482:CSOAHI > 2.0.CO;2.

Hubbert, J. C., and V. N. Bringi, 1995: An iterative filtering technique for the analysis of copolar differential phase and dual-frequency radar measurements. J. Atmos. Oceanic Technol., 12, 643-648, https://doi.org/10.1175/1520-0426(1995)012<0643:AIFTFT > 2.0.CO;2.

—_, and — 2000: The effects of three-body scattering on differential reflectivity signatures. J. Atmos. Oceanic Technol., 17, 51-61, https://doi.org/10.1175/1520-0426(2000)017<0051: TEOTBS $>2.0$.CO;2.

Jewell, R., and J. Brimelow, 2009: Evaluation of Alberta hail growth model using severe hail proximity soundings from the United States. Wea. Forecasting, 24, 1592-1609, https://doi. org/10.1175/2009WAF2222230.1.

Johnson, A. W., and K. E. Sugden, 2014: Evaluation of soundingderived thermodynamic and wind-related parameters associated 
with large hail events. Electron. J. Severe Storms Meteor., 9 (5), https://ejssm.org/ojs/index.php/ejssm/article/viewArticle/137.

Jung, Y., M. Xue, and G. Zhang, 2010: Simulations of polarimetric radar signatures of a supercell storm using a two-moment bulk microphysics scheme. J. Appl. Meteor. Climatol., 49, 146-163, https://doi.org/10.1175/2009JAMC2178.1.

Kalina, E. A., K. Friedrich, B. C. Motta, W. Deierling, G. T. Stano, and N. N. Rydell, 2016: Colorado plowable hailstorms: Synoptic weather, radar, and lightning characteristics. Wea. Forecasting, 31, 663-693, https://doi.org/10.1175/WAF-D-15-0037.1.

Knight, C. A., and N. C. Knight, 2001: Hailstorms. Severe Convective Storms, Meteor. Monogr., No. 50, Amer. Meteor. Soc., 223-248, https://doi.org/10.1175/0065-9401-28.50.223.

Kumjian, M. R., 2013a: Principles and applications of dual-polarization weather radar. Part I: Description of the polarimetric radar variables. J. Oper. Meteor., 1, 226-242, https://doi.org/10.15191/ nwajom.2013.0119.

_ 2013b: Principles and applications of dual-polarization weather radar. Part II: Warm and cold season applications. J. Oper. Meteor., 1, 243-264, https://doi.org/10.15191/nwajom.2013.0120.

- 2013c: Principles and applications of dual-polarization weather radar. Part III: Artifacts. J. Oper. Meteor., 1, 265-274, https:// doi.org/10.15191/nwajom.2013.0121.

_ 2018: Weather radars. Remote Sensing of Clouds and Precipitation, C. Andronache, Ed., Springer-Verlag, 15-63.

_- and Z. J. Lebo, 2016: Large accumulations of small hail. 28th Conf. on Severe Local Storms, Portland, OR, Amer. Meteor. Soc., 8A.4, https://ams.confex.com/ams/28SLS/webprogram/ Paper301237.html.

— J. C. Picca, S. Ganson, A. V. Ryzhkov, J. Krause, D. Zrnić, and A. Khain, 2010: Polarimetric characteristics of large hail. 25th Conf. on Severe Local Storms, Denver, CO, Amer. Meteor. Soc., 11.2, https://ams.confex.com/ams/25SLS/techprogram/ paper_176043.htm.

_ S. M. Ganson, and A. V. Ryzhkov, 2012: Raindrop freezing in deep convective updrafts: A microphysical and polarimetric model. J. Atmos. Sci., 69, 3471-3490, https://doi.org/10.1175/ JAS-D-12-067.1.

— A. P. Khain, N. BenMoshe, E. Ilotoviz, A. V. Ryzhkov, and V. T. J. Phillips, 2014: The anatomy and physics of $Z_{\mathrm{DR}}$ columns: Investigating a polarimetric radar signature with a spectral bin microphysical model. J. Appl. Meteor. Climatol., 53, 1820-1843, https://doi.org/10.1175/JAMC-D-13-0354.1.

— Z. J. Lebo, and H. C. Morrison, 2015: On the mechanisms of rain formation in an idealized supercell storm. Mon. Wea. Rev., 143, 2754-2773, https://doi.org/10.1175/MWR-D-14-00402.1.

— Y. Y. P. Richardson, T. Meyer, K. A. Kosiba, and J. Wurman, 2018: Resonance scattering effects in wet hail observed with the dual-X-band-frequency, dual-polarization Doppler on Wheels radar. J. Appl. Meteor. Climatol., 57, 2713-2731, https://doi.org/ 10.1175/JAMC-D-17-0362.1.

— C. Martinkus, O. P. Prat, S. Collis, M. van Lier-Walqui, and H. C. Morrison, 2019: A moment-based polarimetric radar forward operator for rain microphysics. J. Appl. Meteor. Climatol., 58, 113-130, https://doi.org/10.1175/JAMC-D-18-0121.1.

Loeffler, S., and M. R. Kumjian, 2018: Quantifying the separation of enhanced $Z_{\mathrm{DR}}$ and $K_{\mathrm{DP}}$ regions in nonsupercell tornadic storms. Wea. Forecasting, 33, 1143-1157, https://doi.org/10.1175/ WAF-D-18-0011.1.

Markowski, P. M., and Y. P. Richardson, 2010: Mesoscale Meteorology in Midlatitudes. 1st ed. Wiley-Blackwell, $407 \mathrm{pp}$.

Morrison, H., M. R. Kumjian, C. P. Martinkus, O. P. Prat, and M. van Lier-Walqui, 2019: A general $N$-moment normalization method for deriving raindrop size distribution scaling relationships. J. Appl. Meteor. Climatol., 58, 247-267, https://doi.org/ 10.1175/JAMC-D-18-0060.1.

Nelson, S. P., 1983: The influence of storm flow structure on hail growth. J. Atmos. Sci., 40, 1965-1983, https://doi.org/10.1175/ 1520-0469(1983)040<1965:TIOSFS $>2.0$.CO;2.

NWS, 2014: Warm dry weather and drought return to the borderland. National Weather Service (El Paso, TX) Southwest Weather Bull. Spring-Summer 2014, https://www.weather.gov/media/ epz/swww/swwb2014a.pdf.

Ortega, K. L., 2018: Evaluating multi-radar, multi-sensor products for surface hail-fall diagnosis. Electron. J. Severe Storms Meteor., 13 (1), https://www.ejssm.org/ojs/index.php/ejssm/ article/viewFile/163/.

, T. M. Smith, K. L. Manross, A. G. Kolodziej, K. A. Scharfenberg, A. Witt, and J. J. Gourley, 2009: The Severe Hazards Analysis and Verification Experiment. Bull. Amer. Meteor. Soc., 90, 1519-1530, https://doi.org/10.1175/2009BAMS2815.1.

_ J. M. Krause, and A. V. Ryzhkov, 2016: Polarimetric radar characteristics of melting hail. Part III: Validation of the algorithm for hail size discrimination. J. Appl. Meteor. Climatol., 55, 829-848, https://doi.org/10.1175/JAMC-D-15-0203.1.

Parker, M. D., 2014: Composite VORTEX2 supercell environments from near-storm soundings. Mon. Wea. Rev., 142, 508-529, https:// doi.org/10.1175/MWR-D-13-00167.1.

Picca, J. C., and A. V. Ryzhkov, 2012: A dual-wavelength polarimetric analysis of the 16 May 2010 Oklahoma City extreme hailstorm. Mon. Wea. Rev., 140, 1385-1403, https://doi.org/ 10.1175/MWR-D-11-00112.1.

Rasmussen, R. M., and A. J. Heymsfield, 1987: Melting and shedding of graupel and hail. Part I: Model physics. J. Atmos. Sci., 44, 2754-2763, https://doi.org/10.1175/1520-0469(1987)044<2754: MASOGA $>2.0 . \mathrm{CO} ; 2$.

Roeder, P., 2012: Severe Weather in North America: Perils, Risks, and Insurance. Knowledge Series: Natural Hazards, Munich RE, $274 \mathrm{pp}$.

Ryzhkov, A. V., 2001: Interpretation of polarimetric radar covariance matrix for meteorological scatterers: Theoretical analysis. J. Atmos. Oceanic Technol., 18, 315-328, https://doi.org/ 10.1175/1520-0426(2001)018<0315:IOPRCM > 2.0.CO;2.

2007: The impact of beam broadening on the quality of radar polarimetric data. J. Atmos. Oceanic Technol., 24, 729-744, https://doi.org/10.1175/JTECH2003.1.

—, T. J. Schuur, D. W. Burgess, P. L. Heinselman, S. E. Giangrande, and D. S. Zrnić, 2005: The Joint Polarization Experiment: Polarimetric rainfall measurements and hydrometeor classification. Bull. Amer. Meteor. Soc., 86, 809-824, https://doi.org/10.1175/BAMS-86-6-809.

—, M. Pinsky, A. Pokrovsky, and A. Khain, 2011: Polarimetric radar observation operator for a cloud model with spectral microphysics. J. Appl. Meteor. Climatol., 50, 873-894, https:// doi.org/10.1175/2010JAMC2363.1.

, M. R. Kumjian, S. M. Ganson, and A. P. Khain, 2013a: Polarimetric radar characteristics of melting hail. Part I: Theoretical simulations using spectral microphysical modeling. J. Appl. Meteor. Climatol., 52, 2849-2870, https://doi.org/ 10.1175/JAMC-D-13-073.1.

, ——, — a and P. Zhang, 2013b: Polarimetric radar characteristics of melting hail. Part II: Practical implications. J. Appl. Meteor. Climatol., 52, 2871-2886, https://doi.org/10.1175/JAMC-D-13-074.1.

Scotten, K. N., T. T. Lindley, J. B. Boettcher, M. Martinez, and J. Puryear, 2013: Dual-polarization radar observations of an enhanced precipitation hail and flash flood event. 19th Conf. 
on Planned and Inadvertent Weather Modification, Austin, TX, Amer. Meteor. Soc., 3.5, https://ams.confex.com/ams/ 93Annual/webprogram/Paper218293.html.

Smith, P. L., 2010: The unit symbol for the logarithmic scale of radar reflectivity factors. J. Atmos. Oceanic Technol., 27, 615-616, https://doi.org/10.1175/2009JTECHA1360.1.

Snyder, J. C., H. B. Bluestein, G. Zhang, and S. J. Frasier, 2010: Attenuation correction and hydrometeor classification of highresolution, X-band, dual-polarized mobile radar measurements in severe convective storms. J. Atmos. Oceanic Technol., 27, 1979-2001, https://doi.org/10.1175/2010JTECHA1356.1.

Tessendorf, S. A., L. J. Miller, K. C. Wiens, and S. A. Rutledge, 2005: The 29 June supercell observed during STEPS. Part I: Kinematics and microphysics. J. Atmos. Sci., 62, 4127-4150, https://doi.org/10.1175/JAS3585.1.

Ulbrich, C. W., and D. Atlas, 1982: Hail parameter relations: A comprehensive digest. J. Appl. Meteor., 21, 22-43, https://doi.org/ 10.1175/1520-0450(1982)021<0022:HPRACD > 2.0.CO;2.

Wakimoto, R. M., and V. N. Bringi, 1988: Dual-polarization observations of microbursts associated with intense convection: The 20 July storm during the MIST project. Mon. Wea. Rev., 116, 1521-1539, https://doi.org/10.1175/1520-0493(1988) 116<1521:DPOOMA > 2.0.CO;2.

Wallace, R., K. Friedrich, B. Meier, W. Deierling, E. A. Kalina, P. T. Schlatter, and M. Serpas, 2018: Observing deep hail accumulations on the Colorado and Wyoming Front Range. 29th Conf. on Severe Local Storms, Stowe, VT, Amer. Meteor. Soc., 11.2, https://ams.confex.com/ams/29SLS/webprogram/ Paper348484.html.

Wang, Y., and V. Chandrasekar, 2009: Algorithm for estimation of the specific differential phase. J. Atmos. Oceanic Technol., 26, 2565-2578, https://doi.org/10.1175/2009JTECHA1358.1.

Ward, A., M. R. Kumjian, M. J. Bunkers, S. Bieda, and B. J. Simpson, 2018: Using polarimetric radar data to identify potentially hazardous hail accumulations. 34th Conf. on Environmental Information Processing Technologies, Austin, TX, Amer. Meteor. Soc., 11B.1, https://ams.confex.com/ams/ 98Annual/webprogram/Paper326596.html.

Witt, A., N. D. Eilts, G. J. Stumpf, J. T. Johnson, E. D. Mitchell, and K. W. Thomas, 1998: An enhanced hail detection algorithm for the WSR-88D. Wea. Forecasting, 13, 286-303, https://doi.org/10.1175/1520-0434(1998)013<0286:AEHDAF> 2.0.CO;2.

Zrnić, D. S., 1987: Three-body scattering produces precipitation signature of special diagnostic value. Radio Sci., 22, 76-86, https://doi.org/10.1029/RS022i001p00076.

_ , and A. V. Ryzhkov, 1999: Polarimetry for weather surveillance radars. Bull. Amer. Meteor. Soc., 80, 389-406, https://doi.org/ 10.1175/1520-0477(1999)080<0389:PFWSR > 2.0.CO;2.

, G. Zhang, V. Melnikov, and J. Andrić, 2010: Three-body scattering and hail size. J. Appl. Meteor. Climatol., 49, 687-700, https://doi.org/10.1175/2009JAMC2300.1. 